
upf. $\begin{array}{ll}\text { Universitat } & \text { Department } \\ \text { Pompeu Fabra } & \text { of Economics and Business }\end{array}$ Barcelona

Economics Working Paper Series

Working Paper No. 1622

\title{
Collateral booms and information depletion
}

Vladimir Asriyan, Luc Laeven, and Alberto Martin

Updated version: January 2019

(November 2018) 


\title{
Collateral Booms and Information Depletion
}

\author{
Vladimir Asriyan, Luc Laeven and Alberto Martin*
}

January 21, 2019

\begin{abstract}
We develop a new theory of information production during credit booms. In our model, entrepreneurs need credit to undertake investment projects, some of which enable them to divert resources towards private consumption. Lenders can protect themselves from such diversion in two ways: collateralization and costly screening, which generates durable information about projects. In equilibrium, the collateralization-screening mix depends on the value of aggregate collateral. High collateral values raise investment and economic activity, but they also raise collateralization at the expense of screening. This has important dynamic implications. During credit booms driven by high collateral values (e.g. real estate booms), the economy accumulates physical capital but depletes information about investment projects. As a result, collateral-driven booms end in deep crises and slow recoveries: when booms end, investment is constrained both by the lack of collateral and by the lack of information on existing investment projects, which takes time to rebuild. We provide new empirical evidence using US firm-level data in support of the model's main mechanism.
\end{abstract}

JEL: E32, E44, G01, D80.

Keywords: Credit Booms, Collateral, Information Production, Crises, Misallocation.

*Asriyan: CREI, UPF, BGSE and CEPR. Laeven: ECB and CEPR. Martin: ECB, CREI, BGSE and CEPR. We thank Manuel Amador, Gadi Barlevy, Javier Bianchi, Jordi Gali, Nicola Gennaioli, Christian Leuz, Olivia Mitchell, John Moore, Fabrizio Perri, Rafael Repullo, Victoria Vanasco, Jaume Ventura, and seminar participants at CREi-UPF, IIES, University of Cambridge, Bocconi, Minneapolis Fed, Philadelphia Fed, Workshop on Bubbles in Macroeconomics Barcelona 2017, SED meetings Edinburgh 2017, Barcelona GSE Summer Forum 2018 and AEA meetings Atlanta 2019 for helpful suggestions and comments. Asriyan and Martin acknowledge support from the Spanish Ministry of Economy, Industry and Competitiveness through the I+D Excelencia grant (grant ECO2016-79823-P) and through the Severo Ochoa Programme for Centres of Excellence in R\&D grant (SEV-2015-0563); from the Generalitat de Catalunya through the CERCA Programme grant (2014 SGR-830); and from the Barcelona GSE Research Network. Martín also acknowledges support from the European Research Council under the EU Seventh Framework Programme (FP7/2007-2013) ERC Consolidator Grant (615651-MacroColl). These are the views of the authors and not necessarily those of the ECB. Sandra Daudignon and Ilja Kantorovitch provided excellent research assistance. 


\section{Introduction}

Credit booms, defined as periods of rapid credit growth, are common phenomena in both advanced and emerging economies ${ }^{1}$ They are generally accompanied by a strong macroeconomic performance, including high asset prices, and high rates of investment and GDP growth 2 Yet, the conventional wisdom is to view them with suspicion. First, credit booms are often perceived to fuel resource misallocation: high asset prices and a positive economic outlook may lead to the relaxation of lending standards and, consequently, to the funding of relatively inefficient activities. ${ }^{3}$ As the old banker maxim goes, "bad loans are made in good times." Second, credit booms often end in crises that are followed by protracted periods of low growth 4

This conventional wisdom raises important questions. What determines the allocation of resources during credit booms? How does this allocation shape the macroeconomic effects of credit booms, and of their demise? And finally, are all credit booms alike? In this paper, we develop a new theory of information production during credit booms to address these questions and exploit US data to provide new empirical evidence of the theory's main predictions.

We study an economy that is populated by borrowers (entrepreneurs) and lenders. Entrepreneurs have access to long-lived investment projects but need external funding to undertake them; lenders, instead, have resources but they lack the ability to run investment projects. Absent any friction, this would not be a problem, as lenders could simply provide credit to entrepreneurs with productive investment opportunities. We introduce a friction, however, by assuming that some projects enable entrepreneurs to divert resources for private consumption (i.e., they yield non-contractible private benefits).

If they are to break even, lenders need to protect themselves against such diversion by entrepreneurs. They have two ways of doing so. The first is collateralization. Entrepreneurs are endowed with assets (e.g. real estate), and lenders can ask them to retain "skin in the game" by posting these assets as collateral. The second is costly screening. Lenders may engage in costly information production to ensure that the projects undertaken by entrepreneurs do not permit resource diversion. We make two assumptions regarding screening. First, the cost of screening an individual project in any given period is increasing in the economy's aggregate amount of screening in that period. This assumption captures the intuitive notion that there is an increasing cost of producing information in any given period due, for instance, to some

\footnotetext{
${ }^{1}$ See Mendoza and Terrones (2008) and Bakker et al. (2012) for a brief discussion on the formal definition and empirical identification of credit booms. Claessens et al. (2011) use a different approach and study "credit cycles," but they also find them to be common among advanced economies.

2 Mendoza and Terrones (2008) study empirically the macroeconomic conditions during credit booms.

${ }^{3}$ See, for example, García-Santana et al. (2016) and Gopinath et al. (2017).

${ }^{4}$ See Schularick and Taylor (2012) and Krishnamurthy and Muir (2017).
} 
fixed underlying factor 5 Second, the information generated through screening is long-lived, and it accompanies the project throughout its life.

The key insight of the model is that, in equilibrium, the relative intensity of collateralization vs screening depends on the scarcity of entrepreneurial collateral, i.e., on the price of real estate. When the price of real estate is low, lenders rely largely on screening. Since only few investment projects can be funded via collateralization, the return to investment at the margin - and thus to screening - is high. This raises the equilibrium level of screening and thus the amount of information on existing projects. Instead, when the price of real estate is high, the equilibrium mix of screening to collateralization is low. In this case, since many investment projects can be funded via collateralization, the marginal return to investment is low. This reduces equilibrium screening and thus the amount of information on existing projects.

This insight has powerful implications for the effects of collateral-driven credit booms. When the economy enters a collateral boom, the price of real estate rises and credit, investment and output all expand together. But, for the reasons outlined above, lenders rely more on collateralization and less on screening. Therefore, even as the economy booms, the amount of information on existing projects falls: in this sense, the boom is accompanied by a 'depletion' of information. When the boom ends and the price of real estate falls, credit, investment, and output fall as well, but they do so for two reasons: (i) all else equal, the scarcity of collateral means that lenders must increase their reliance on costly screening, and; (ii) this need for screening is especially strong because information has been 'depleted' during the boom. For these reasons, the end of a collateral boom is accompanied by a large crash and a slow recovery, i.e., a transitory "undershooting" of economic activity relative to its new long-run level.

Besides this general insight, the model sheds light on three key debates regarding credit booms and their macroeconomic effects. First, it shows that not all credit booms are alike. Richter et al. (2017) and Gorton and Ordoñez (2016) have recently referred to "good" and "bad" booms, depending on whether they end in crises or not. Through the lens of our model, the defining feature of booms lies in the shock that drives them. In particular, unlike collateral-driven booms, productivity-driven booms do not generate information depletion: by raising the return to investment, an increase in productivity actually raises equilibrium screening and information production. Thus, the end of productivity-driven booms does not exhibit a deep crisis with an undershooting of economic activity. Second, the model speaks to the recent literature on asset price bubbles (e.g. Martin and Ventura (2018)). In essence, one can interpret collateral-driven booms as the result of bubbles, which raise collateral but do not affect economic fundamentals. Under this interpretation, the model highlights a hitherto

\footnotetext{
${ }^{5}$ Screening borrowers, for instance, may require trained loan officers or experts, and information gathering and processing infrastructure, which are difficult to change in the short run.
} 
unexplored cost of bubbles that surfaces when they burst: while they last, bubbles deplete information on existing projects. Third, the model also shows why credit booms can lead to resource or factor misallocation: by reducing information, collateral booms raise dispersion in the productivity of investment. However, there is a positive counterpart to this increase in dispersion, as the economy saves on information costs.

Finally, we study the normative properties of our economy. Intuitively, it may seem that market participants produce too little information during booms: if less information were depleted during booms, the busts would be less severe and recoveries faster. We show, however, that this intuition is incorrect. Since agents are rational, they correctly anticipate the value of information in future states of nature. Thus, even in the midst of a collateral boom, agents understand that - when the bust comes - screened projects will be very valuable and they will be able to appropriate this value. If anything, we find that, due to pecuniary externalities resulting from market prices affecting financial constraints, agents produce too much information! For information generation to be inefficiently low, we argue that there must be additional distortions that prevent agents from fully internalizing the social return to information production. We explore two such distortions: external economies in the screening technology and frictions in the market for projects.

We test three central predictions of the theory on US firm-level data from COMPUSTAT. First, as is standard in the presence of financial frictions, the theory predicts that a rise in collateral values should coincide with an increase in investment and output. Second, and more central to the theory, an increase in collateral values should lead to information depletion, i.e., to a decline in screened investment. Finally, the theory predicts that a decline in collateral values should reduce investment and output, the more so the lower is the amount of information on existing projects, i.e., the share of past investment that has been screened.

Testing the empirical relevance of the model's main predictions is nontrivial for at least two reasons. First, all three predictions refer to the effect of collateral values on the amount and composition of investment. Assessing this in the data requires identifying changes in collateral values that are orthogonal to other economic conditions, such as productivity, which may affect investment on their own. We deal with this by following Chaney et al. (2012) and estimating the impact of real estate prices on corporate investment using instrumental variables. Second, the main prediction of the model is that an increase in net worth or collateral reduces the economy's reliance on screening, so that there is less information on existing projects. Assessing this in the data requires a measure of screening intensity or, analogously, of the availability of information on existing projects. Given the lack of a generally accepted measure of such information, we adopt a holistic approach and use three alternative measures of information at the firm level: the bid-ask spread on the firm's stock, the number 
of financial analysts that follow the firm, and the ratio of intangible assets to tangible fixed assets of the sector in which the firm operates.

Our empirical results are consistent with the main predictions of the model. First, a firm's investment is increasing in the value of its real estate. Second, this effect is stronger for firms on which there is less information, as measured through the bid-ask spread, the number of analysts covering the firm or the ratio of intangible to tangible assets of the sector in which the firm operates. Finally, to assess how the distribution of investment during the boom affects the severity of the subsequent bust, we analyze evidence at the state level during the recent housing boom and bust in the United States. We find that, at the state level, investment during the bust years (2007-2012) is negatively correlated with the share of investment that was undertaken by high-spread firms during the boom (2001-2006).

More broadly, our theory is consistent with various strands of stylized evidence. First, there is ample evidence showing that investment is positively correlated with collateral values (Peek and Rosengren, 2000; Gan, 2007; Chaney et al., 2012). Second, there is also evidence that lending standards, and in particular lenders' information on borrowers, deteriorates during booms Asea and Blomberg, 1998; Keys et al., 2010; Becker et al., 2016; Lisowsky et al., 2017). Third, and focusing more specifically on collateral booms, Doerr (2018) finds that the US housing boom of the 2000s led to a reallocation of capital and labor to less productive firms. Fourth, there is evidence that credit booms that are accompanied by house price booms (Richter et al., 2017) and that are characterized by low productivity growth (Gorton and Ordoñez, 2016) are more likely to end in crises. All of these findings are consistent with the model's main predictions.

On the theoretical front, we are not the first to consider the link between information production and economic booms and busts (Van Nieuwerburgh and Veldkamp, 2006; Ordoñez, 2013; Gorton and Ordoñez, 2014, 2016; Fajgelbaum et al., 2017; Straub and Ulbricht, 2017). Within this work, the closest to us are the papers by Gorton and Ordoñez. Like them, we focus on the interaction between information generation in the credit market and credit booms. Also like them, we predict that booms are characterized by a deterioration of information. There is a key difference between our framework and theirs, however. In their framework, information is about the quality of entrepreneurs' collateral, whereas in our model it is about the quality of entrepreneurs' investment projects. Because of this, information production deters investment in their framework, and - in fact - it is information production that triggers a crisis: once lenders can distinguish between collateral of high and low quality, there is a fall in lending and investment. In our framework, instead, information production helps sustain investment. Differently from Gorton and Ordoñez, it is the crisis that triggers information production, as the lack of collateral makes it worthwhile for market participants to ramp up screening. 
Our paper also speaks to the growing literature on the cost of credit booms and busts. On the one hand, we have already mentioned the evidence suggesting that credit booms raise misallocation (García-Santana et al., 2016; Gopinath et al., 2017). Our model provides a possible cause of such misallocation: information depletion. Relatedly, our model contributes to the literature on rational bubbles (see Martin and Ventura (2018) for a recent survey) by identifying a hitherto unexplored cost of asset bubbles. By providing collateral, bubbles reduce incentives to generate information and this makes their collapse especially costly.

Conceptually, the theory developed here is related to previous work that studies the optimal choice of technology in the presence of financial frictions. In our model, the equilibrium mix of screened and unscreened investment depends on the availability of collateral. This is reminiscent of Matsuyama (2007), where the lack of borrower net worth may induce a shift towards less productive but more pledgeable technologies. More recently, Diamond et al. (2017) also develop a model in which the equilibrium choice of technology depends on financial conditions: in particular, high expected asset prices in an industry prompt firms to adopt less pledgeable technologies, because they can obtain credit simply by collateralizing assets. This exacerbates the severity of downturns caused by a decline in asset prices, however, because firms' inability to pledge their cash flow prevents them from obtaining credit and leads to their liquidation.

Finally, our paper is also related to the literature studying the determinants of lending standards and their evolution over the business cycle (Manove et al., 2001; Ruckes, 2004; Martin, 2005; Dell'Ariccia and Marquez, 2006, Favara, 2012, Petriconi, 2015). Of these, the work closest to ours is Manove et al. (2001), which studies the relationship between collateral and screening in loan contracts. Their focus is on the contracting problem itself, however, and not on the macroeconomic implications of information production. Ruckes (2004), Gorton and $\mathrm{He}(2008)$ and Petriconi (2015) also study the evolution of screening over the cycle, but they stress the effect of bank competition on the equilibrium choice of screening. Instead, Martin (2005) and Favara (2012) study how the interplay between entrepreneurial net worth and lender incentives can give rise to endogenous lending cycles.

The paper is organized as follows. In Section 2, we present the baseline model. In Section 3 , we characterize the equilibrium and derive our main results. In Section 4, we consider several extensions, and we study the economy's normative properties in Section 5. In Section 6, we present the empirical analysis and results. Finally, we conclude in Section 7. 


\section{The Model}

Time is infinite and discrete, $t=0,1, \ldots$ The economy is populated by overlapping generations of young and old. The objective of individual $i$ of generation $t$ is to maximize her utility

$$
U_{i, t}=E_{t}\left\{C_{i, t+1}\right\}
$$

where $C_{i, t+1}$ is her old age consumption and $E_{t}\{\cdot\}$ is the expectations operator at time $t$.

Each generation consists of two types of individuals, entrepreneurs and savers, each of unit mass. Savers work during youth and save their labor income to finance old age consumption. Entrepreneurs borrow during youth to finance investment, and they produce during old age. There is a risk-neutral international financial market willing to borrow from and lend to domestic agents at a (gross) expected return of $\rho$. Thus, we think of our economy as being small and open, and we refer to $\rho$ as the interest rate.

Savers are endowed with one unit of labor during youth, which they supply inelastically in a competitive labor market. Given their preferences, they save their entire labor income. Their only choice is whether to save in the international financial market at rate $\rho$ or lend to the entrepreneurs in the domestic credit market at an expected rate $E_{t} R_{t+1}$. Of course, in equilibrium it must be that $E_{t} R_{t+1}=\rho$.

Entrepreneurs engage in two types of productive activities. First, young entrepreneurs run investment technologies (or projects), which transform consumption goods in period $t$ into capital in period $t+1$. Capital depreciates at rate $\delta$ and is reversible. Second, old entrepreneurs combine capital with labor to produce the economy's consumption good. In particular, entrepreneurs produce according to a Cobb-Douglas technology: $F_{t}\left(l_{i, t}, k_{i, t}\right)=A_{t}$.

$k_{i, t}^{\alpha} \cdot l_{i, t}^{1-\alpha}$, where $k_{i, t}$ is the capital stock of entrepreneur $i, l_{i, t}$ is the labor hired by entrepreneur $i, A_{t}$ reflects aggregate productivity, and $\alpha \in(0,1)$.

Entrepreneurs are endowed with "trees" whose market value in period $t$ is denoted by $q_{t}$. Since entrepreneurs can borrow against this market value, we refer to trees indistinctly as the net worth or collateral of entrepreneurs. In the main analysis, we take the collateral value $q_{t}$ to be exogenous, but we endogenize it in Section 4.1. We think of these trees as an asset distinct from capital, e.g. real estate or land, whose valuation affects entrepreneurs' net worth but is orthogonal to their investment opportunities. Both $q_{t}$ and $A_{t}$ are potentially random and are the only sources of aggregate uncertainty in our economy.

The investment technology operated by entrepreneurs to produce capital is as follows. Each unit of investment at time $t$ produces a unit of capital at time $t+1$. Each unit of capital, however, is of uncertain quality: with probability $\mu$, this capital is of type $\theta=H$; with probability $1-\mu$, it is of type $\theta=L$. The quality of each unit of capital is independent 
of the rest and, once produced, persists throughout the unit's lifetime. We initially assume that both types of capital are equally productive ${ }^{6}$ The $L$-type capital, however, suffers from an "agency" problem in that it allows the entrepreneur to abscond with all the resources generated by it. Thus, the key difference between both types is that the income generated by $H$-type capital can be pledged to outside creditors, whereas that of $L$-type cannot.7

Thus, at any point in time, entrepreneurs have two sources of collateral that can be pledged to outside creditors: trees (or outside collateral, which is exogenous to production) and the return to $H$-type capital (or inside collateral, which is endogenously produced through investment). The central feature of our environment is that, prior to investing in a given technology, young entrepreneurs can reduce their investment uncertainty through screening. In particular, before investing in a given unit of capital, a young entrepreneur can pay a screening cost $\psi_{t}$ to produce a public signal about the unit's type: for simplicity, we assume throughout that this signal is perfect. Upon having observed the signal, the entrepreneur can choose whether or not to invest in this unit. Any signal generated through screening is public information throughout the unit's lifetime, although the history or past performance of the unit is not. Entrepreneurs may therefore own both, units of "screened capital" whose types are known, and units of "unscreened capital" whose types are unknown.

We use $k_{t}^{\theta}\left(k_{i, t}^{\theta}\right)$ to denote the economy's (entrepreneur $i$ 's) stock of screened capital of type $\theta \in\{H, L\}$, and $k_{t}^{\mu}\left(k_{i, t}^{\mu}\right)$ to denote the economy's (entrepreneur $i$ 's) stock of unscreened capital. Since all units are equally productive, only the total capital stock is relevant for the economy's (entrepreneur's) production and it is given by $k_{t}=k_{t}^{H}+k_{t}^{L}+k_{t}^{\mu}\left(k_{i, t}=k_{i, t}^{H}+k_{i, t}^{L}+k_{i, t}^{\mu}\right)$.

\subsection{Labor, asset and credit markets}

Old entrepreneurs interact with young savers in a competitive labor market. At the beginning of period $t$, given her capital stock $k_{i, t}$, maximization by entrepreneur $i$ implies

$$
l_{i, t}=\left[\frac{A_{t} \cdot(1-\alpha)}{w_{t}}\right]^{\frac{1}{\alpha}} \cdot k_{i, t},
$$

where $w_{t}$ is the wage rate per unit of labor. Equation (1) is the labor demand of entrepreneur $i$, which results from hiring labor until its marginal product equals the wage. Since the aggregate

\footnotetext{
${ }^{6}$ We incorporate productivity heterogeneity in Section 4.2 , where we study how credit booms affect measured factor misallocation.

${ }^{7}$ This stark assumption is convenient but inessential. Appendix B.5 shows that our main results are unchanged as long as $H$-type capital is more pledgeable than $L$-type capital.
} 
supply of labor is one, market clearing implies that:

$$
w_{t}=A_{t} \cdot(1-\alpha) \cdot k_{t}^{\alpha}
$$

Thus, Equation (2) indicates that the wage equals the marginal product of labor evaluated at the aggregate capital-labor ratio 8 We use

$$
r_{t}=A_{t} \cdot \alpha \cdot k_{t}^{\alpha-1}
$$

to denote the marginal product of capital. Equations (11)-(3) are standard, so we impose them throughout our analysis.

Entrepreneurs can buy and sell capital in a competitive market. We use $p_{t}^{\theta}$ and $p_{t}^{\mu}$ to denote the market prices of a unit of screened capital of type- $\theta$ and of unscreened capital, respectively. After producing in period $t$, old entrepreneur $i$ is left with $(1-\delta) \cdot k_{i, t}^{j}$ units of capital of "type" $j \in\{H, L, \mu\}$. Her only choice at this point is whether to sell his units of capital in the market or to reverse and consume them. It follows immediately that she will strictly prefer to sell all units of capital whose price exceeds one, she will be indifferent between selling and consuming those units whose price is exactly one, and she will strictly prefer to consume any units whose price is lower than one. Thus, old entrepreneurs can obtain $\max \left\{p_{t}^{j}, 1\right\}$ for each undepreciated unit of type- $j$ capital after production.

In order to invest and purchase capital, young entrepreneurs obtain financing in the credit market. Credit is supplied by competitive banks that are run by savers. This implies that they are willing to lend to entrepreneurs as long as the expected return of doing so is no lower than $\rho$. Banks also run the screening technology used to identify the quality of investment $9^{9}$ We make two assumptions regarding this technology, which we interpret in Appendix B.1 as the result of competition within a banking sector that provides screening services by hiring experts (e.g. savers) who are heterogeneous in their screening costs. First, screening is costly: letting $\psi_{t}$ denote the cost of screening a unit of investment in period $t$, we assume that $\psi_{t} \geq 0$. Second, the cost is increasing in the aggregate units of investment that are screened $s_{t}$, i.e., $\psi_{t}=\psi\left(s_{t}\right)$ with $\psi(0)=0$ and $\psi^{\prime}(\cdot)>0$. This last assumption captures the intuitive notion that there is a limit to the amount of information that the economy can produce in any given period.

Entrepreneurs demand credit from banks, both against their trees and against the income generated by their investment. Since trees are being fully pledgeable, entrepreneurs can borrow

\footnotetext{
${ }^{8}$ Since all entrepreneurs use the same capital-labor ratio, this must also be the aggregate one.

${ }^{9}$ For simplicity, we assume throughout that old or pre-existing units of capital cannot be screened. This assumption is relaxed in Appendix B.6.
} 
an amount $q_{t}$ against them 10 The income generated by investment projects, however, is not fully pledgeable as the existence of $L$-type capital gives rise to a borrowing limit. In particular, if we let $f_{i, t}$ denote the credit extended to entrepreneur $i$ against her projects, and $R_{t+1}$ denote the (potentially state-contingent) interest rate on this credit, then the maximum repayment that she can credibly promise in each state is:

$R_{t+1} \cdot f_{i, t} \leq r_{t+1} \cdot\left(k_{i, t+1}^{H}+\mu \cdot k_{i, t+1}^{\mu}\right)+(1-\delta) \cdot\left(\max \left\{p_{t+1}^{H}, 1\right\} \cdot k_{i, t+1}^{H}+\max \left\{p_{t+1}^{\mu}, 1\right\} \cdot \mu k_{i, t+1}^{\mu}\right)$,

Note that, by the law of large numbers, a fraction $\mu$ of the entrepreneur's unscreened capital is of $H$-type and is thus fully pledgeable.

We do not impose any restrictions on the state-contingency of contracts. Since perfect competition among banks entails $E_{t} R_{t+1}=\rho$ in equilibrium, Equation (4) implies:

$\rho \cdot f_{i, t} \leq E_{t}\left\{r_{t+1} \cdot\left(k_{i, t+1}^{H}+\mu \cdot k_{i, t+1}^{\mu}\right)+(1-\delta) \cdot\left(\max \left\{p_{t+1}^{H}, 1\right\} \cdot k_{i, t+1}^{H}+\max \left\{p_{t+1}^{\mu}, 1\right\} \cdot \mu k_{i, t+1}^{\mu}\right)\right\}$.

Equation (5) states that entrepreneurs can only borrow against the discounted value of expected income generated by the units of capital that have been screened and are known to be $H$-type, and by the share of the unscreened units of capital that are expected to be $H$-type.

\subsection{Entrepreneurs' problem}

We now turn to the problem of a young entrepreneur $i$, who in period $t$ must decide how much to invest and how many units of capital to purchase in the market for capital. Let $x_{i, t}^{j}$ and $z_{i, t}^{j}$ respectively denote the entrepreneur's production and purchases of type- $j$ capital.

Entrepreneur $i$ takes factor prices and the screening cost as given, and chooses his units of capital $\left\{k_{i, t+1}^{j}\right\}_{j}$, its production and purchases $\left\{x_{i, t}^{j}\right\}_{j}$ and $\left\{z_{i, t}^{j}\right\}_{j}$, and screening $s_{i, t}$ to maximize expected old age consumption,

$$
E_{t}\left\{r_{t+1} \cdot k_{i, t+1}+(1-\delta) \cdot \sum_{j=H, L, \mu} \max \left\{p_{t+1}^{j}, 1\right\} \cdot k_{i, t+1}^{j}\right\}-\rho \cdot f_{i, t},
$$

\footnotetext{
${ }^{10}$ Equivalently, entrepreneurs can sell a tree in the market for $q_{t}$ and use this amount to invest.
} 
subject to:

$$
\begin{aligned}
q_{t}+f_{i, t} & =\sum_{j=H, L, \mu}\left(x_{i, t}^{j}+p_{t}^{j} \cdot z_{i, t}^{j}\right)+\psi_{t} \cdot s_{i, t} \\
\rho \cdot f_{i, t} & \leq E_{t}\left\{r_{t+1} \cdot\left(k_{i, t+1}^{H}+\mu \cdot k_{i, t+1}^{\mu}\right)+(1-\delta) \cdot\left(\max \left\{p_{t+1}^{H}, 1\right\} \cdot k_{i, t+1}^{H}+\max \left\{p_{t+1}^{\mu}, 1\right\} \cdot \mu \cdot k_{i, t+1}^{\mu}\right)\right\} \\
x_{i, t}^{H} & \leq \mu \cdot s_{i, t}, \\
x_{i, t}^{L} & \leq(1-\mu) \cdot s_{i, t}, \\
k_{i, t+1}^{j} & =x_{i, t}^{j}+z_{i, t}^{j}, \\
s_{i, t} & \geq 0, \quad \text { for } \quad j \in\{H, L, \mu\} .
\end{aligned}
$$

The entrepreneur's old age consumption equals the expected capital income minus interest payments: note that Equation (6) already takes into account that capital will be sold in the market only if its price exceeds one. This consumption is optimized subject to a set of constraints. The first one is the budget constraint, and it says that total spending on investment, capital purchases and screening must equal the value of trees plus any additional borrowing against projects. The second constraint is the borrowing limit, and it says that payments to creditors cannot exceed the pledgeable part of capital income. The third and fourth constraints say that the entrepreneur's ability to produce capital of known quality ( $H$ or $L$ ) is limited by her screening. The final set of constraints states that the entrepreneur's stock of each type of capital is equal to her production and purchases, and that both screening and holdings of capital must be non-negative.

To solve the problem of the individual entrepreneur, we begin with a conjecture that the equilibrium prices of capital are as follows:

$$
p_{t}^{H}=1+\frac{\psi\left(s_{t}\right)}{\mu} ; \quad p_{t}^{\mu}=p_{t}^{L}=1
$$

We will verify shortly that these prices are indeed part of an equilibrium of our economy 11 Given this conjecture, we solve for the entrepreneurial problem to obtain the capital stocks $k_{i, t+1}^{H}, k_{i, t+1}^{L}$, and $k_{i, t+1}^{\mu}$. The solution has the following implications.

First, entrepreneurs never choose to hold $L$-type capital, i.e. $k_{i, t+1}^{L}=0$. The reason for this is simple. Suppose that entrepreneur $i$ pays the screening cost and discovers that the corresponding unit of investment is of type $L$ : she can always do better by not exercising this option and investing in an unscreened unit of capital instead, which is just as productive (and expensive) but more valuable as collateral.

\footnotetext{
${ }^{11}$ We abstract throughout from the possibility of bubbles in the prices of capital.
} 
Second, entrepreneur holds $H$-type capital if and only if it is profitable to do so, i.e.,

$$
k_{i, t+1}^{H} \begin{cases}=0 & \text { if } \frac{E_{t} R_{t+1}^{H}}{\rho}<1+\frac{\psi_{t}}{\mu} \\ \in[0, \infty) & \text { if } \frac{E_{t} R_{t+1}^{H}}{\rho}=1+\frac{\psi_{t}}{\mu} \\ =\infty & \text { if } \frac{E_{t} R_{t+1}^{H}}{\rho}>1+\frac{\psi_{t}}{\mu}\end{cases}
$$

where

$$
E_{t} R_{t+1}^{H} \equiv E_{t}\left\{r_{t+1}+(1-\delta) \cdot\left(1+\frac{\psi_{t+1}}{\mu}\right)\right\}
$$

denotes the expected return of a unit of $H$-type capital, i.e., the present value of its expected marginal product plus its resale value. Equation (8) states that as long as the discounted expected return exceeds the cost of producing (or purchasing) a unit of $H$-type capital, i.e., the sum of investment plus screening costs, the entrepreneur is willing to hold it 12 Note that this condition implies that the entrepreneur is never constrained in her choice of $H$-type capital, which is natural because the income generated by these units is fully pledgeable.

Finally, holdings of unscreened units of capital are given by,

$$
k_{i, t+1}^{\mu}=\left\{\begin{array}{ll}
=0 & \text { if } \frac{E_{t} R_{t+1}^{\mu}}{\rho}<1 \\
\in\left[0, \frac{\rho}{\rho-\mu \cdot E_{t} R_{t+1}^{\mu}} \cdot q_{t}\right] & \text { if } \frac{E_{t} R_{t+1}^{\mu}}{\rho}=1 \\
=\frac{\rho}{\rho-\mu \cdot E_{t} R_{t+1}^{\mu}} \cdot q_{t} & \text { if } \frac{E_{t} R_{t+1}^{\mu}}{\rho} \in\left(1, \frac{1}{\mu}\right) \\
=\infty & \text { if } \frac{E_{t} R_{t+1}^{\mu}}{\rho} \geq \frac{1}{\mu}
\end{array},\right.
$$

where

$$
E_{t} R_{t+1}^{\mu} \equiv E_{t}\left\{r_{t+1}+1-\delta\right\}
$$

denotes the expected return of a unit of unscreened capital. Equation (9) states that the entrepreneur is willing to hold such a unit as long as its expected discounted return exceeds the cost of producing (or purchasing) it. Differently from the case of $H$-type capital, an entrepreneur's holdings of unscreened capital may be constrained by the borrowing limit because the income generated by these units cannot be fully pledged to creditors.

\subsection{Equilibrium}

To determine the equilibrium, we aggregate the behavior of individual entrepreneurs. From Equation (9), any equilibrium must entail $\rho>\mu \cdot E_{t}\left\{r_{t+1}+1-\delta\right\}$, since otherwise en-

\footnotetext{
${ }^{12}$ At the conjectured prices, young entrepreneurs are indifferent between producing an $H$-type unit of capital or purchasing it on the market.
} 
trepreneurs' investment in unscreened capital would be unbounded. This implies that the aggregate stock of unscreened capital is given by:

$$
k_{t+1}^{\mu}=\min \left\{\frac{\rho}{\rho-\mu \cdot E_{t}\left\{r_{t+1}+1-\delta\right\}} \cdot q_{t}, k_{t+1}^{*}\right\} \text {, }
$$

where $k_{t+1}^{*}$ is the stock of unscreened capital consistent with $E_{t} r_{t+1}=\rho+\delta-1.13$ Equation (10) states that entrepreneurs use all of their collateral to finance unscreened investment, unless the collateral is so large that they become unconstrained.

As for $L$-type capital, we must have,

$$
k_{t+1}^{L}=0,
$$

since no entrepreneur wants to hold it. Finally, Equation (8) implies that in equilibrium the discounted return to $H$-type capital must equal its cost of production,

$$
\frac{E_{t}\left\{r_{t+1}+(1-\delta) \cdot\left(1+\frac{\psi\left(s_{t+1}\right)}{\mu}\right)\right\}}{\rho}=1+\frac{\psi\left(s_{t}\right)}{\mu}
$$

where

$$
s_{t}=\max \left\{0, \frac{k_{t+1}^{H}-(1-\delta) \cdot k_{t}^{H}}{\mu}\right\} .
$$

Equation (13) says that screening takes place only if there is aggregate investment in $H$-type capital. If instead the stock of $H$-type capital is falling, there is no need to screen since all units can be purchased from old entrepreneurs.

These conditions were derived under conjecture (7) about equilibrium prices. We now verify that these prices are indeed consistent with equilibrium. At the conjectured price $p_{t}^{H}=1+\frac{\psi\left(s_{t}\right)}{\mu}$, young entrepreneurs are indifferent between purchasing units of $H$-type capital from old entrepreneurs and producing them; old entrepreneurs, in turn, strictly prefer to sell these units as long as $s_{t}>0$ and are indifferent otherwise. Thus, at this price, the market for $H$-type capital clears. For $\mu$-type capital, at the conjectured price $p_{t}^{\mu}=1$, young entrepreneurs are again indifferent between purchasing these units from old entrepreneurs and producing them; old entrepreneurs, in turn, are also indifferent between selling their units and consuming them. Thus, the market for $\mu$-type capital also clears. Finally, $L$-type capital is

\footnotetext{
${ }^{13}$ Formally, using the definition of $r_{t+1}$ in Equation $(3), k_{t+1}^{*}$ satisfies,

$$
E_{t}\left\{\alpha \cdot A_{t+1} \cdot\left(k_{t+1}^{H}+k_{t+1}^{L}+k_{t+1}^{*}\right)^{\alpha-1}\right\}=\rho+\delta-1 .
$$
}


weakly dominated by $\mu$-type capital, so the young do not purchase it. At the conjectured price $p_{t}^{L}=1$, old entrepreneurs are indifferent between selling their capital and consuming it, so the market for $L$-type capital clears as well.

The equilibrium is computed as follows. Given an initial condition $k_{0}^{H}, k_{0}^{L}$, and $k_{0}^{\mu}$, which are the capital units held by the initial generation of old entrepreneurs, and given a stochastic process for the economy's shocks $\left\{q_{t}, A_{t}\right\}_{t \geq 0}$, equations (3) and (10)-(13) jointly characterize the evolution of the equilibrium capital stocks and screening $\left\{k_{t}^{H}, k_{t}^{L}, k_{t}^{\mu}, s_{t-1}\right\}_{t>0}$.

\section{Collateral-driven booms and busts}

We are now ready to characterize the dynamic behavior of the economy. Our main objective is to analyze how the economy behaves during a collateral-driven boom-bust cycle, i.e., an economic cycle driven by fluctuations in entrepreneurial collateral $q_{t}$. Once again, we think of these as fluctuations in entrepreneurial net worth that are orthogonal to investment opportunities, e.g. fluctuations in land or real-estate values. To clarify the role of collateral, we will compare these boom-bust cycles with those driven by fluctuations in productivity, as captured by $A_{t}$.

To simplify the exposition, we gradually build up to the full dynamic analysis of the model. We begin by assuming that $\delta=1$, so that capital depreciates fully in production. By making capital units short-lived, this eliminates the forward-looking nature of screening and essentially makes the economy static. We then set $\delta<1$ and analyze the behavior of the economy in response to unanticipated shocks. This intermediate step enables us to use a simple phase diagram analysis to illustrate the "slow-moving" nature of information, and its interaction with investment and its composition. Finally, we allow for shocks to be anticipated and analyze the behavior of the economy in response to fluctuations in $q_{t}$ (and $A_{t}$ ).

\subsection{Building intuitions: the static model}

When $\delta=1$, capital depreciates fully after production and thus $k_{t+1}^{H}=\mu \cdot s_{t}$, i.e. the economy must produce its entire stock of $H$-type capital by screening in every period. In this case, the equilibrium is described by

$$
k_{t+1}^{\mu}=\min \left\{\frac{\rho}{\rho-\mu \cdot E_{t} r_{t+1}} \cdot q_{t}, k_{t+1}^{*}\right\},
$$

and 

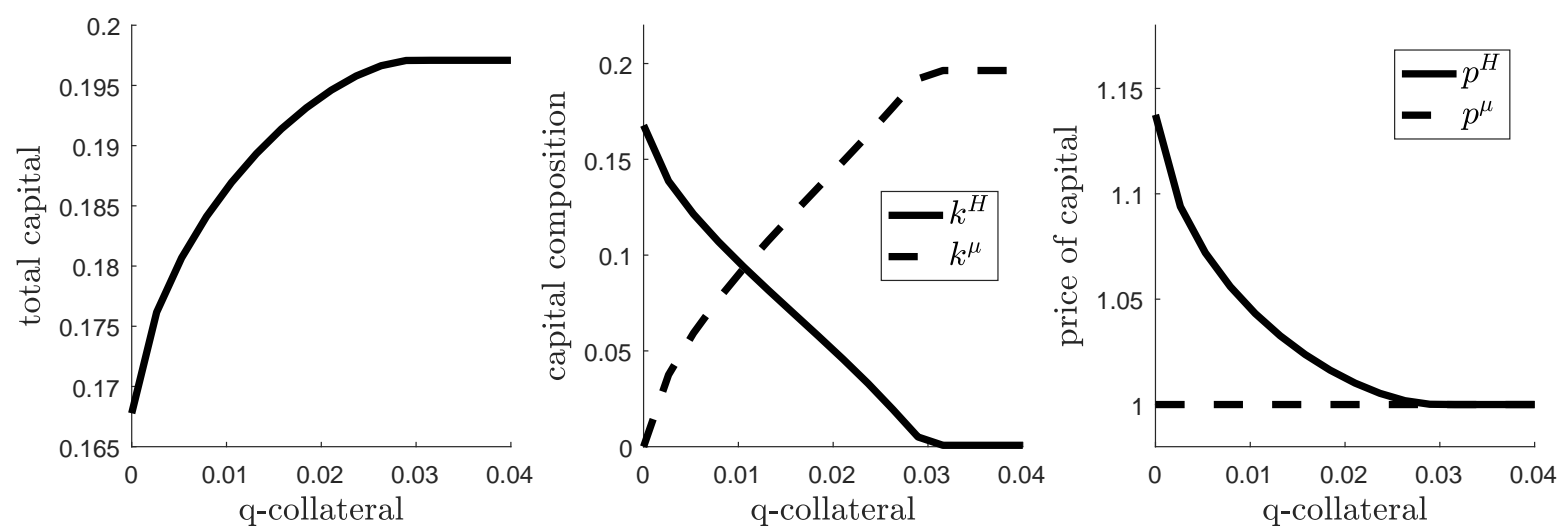

Figure 1: Effects of collateral when $\delta=1$. The figure depicts the equilibrium capital stock, its composition and capital prices, as a function of collateral value $q$, in the economy with full depreciation. The parameter values used to produce the figures are provided in Appendix B.7.

$$
\frac{E_{t} r_{t+1}}{\rho}=1+\frac{\psi\left(\max \left\{\mu^{-1} \cdot k_{t+1}^{H}, 0\right\}\right)}{\mu},
$$

where $r_{t+1}$ is defined in Equation (3) and $k_{t+1}^{*}$ is the unscreened capital consistent with $E_{t} r_{t+1}=\rho$. Equations (14) and (15) are the equivalents of Equations (10) and (13), when $\delta$ is set to equal 1. This economy has no state variables and hence no relevant dynamics. Albeit boring, it is nonetheless useful to illustrate the key role played by entrepreneurial collateral.

To illustrate the behavior of this economy, Figure 1 depicts a comparative statics exercise. For a given value of productivity $A$, it shows the equilibrium capital stock, its composition between $H$-type and unscreened capital, and the price of both types of capital, as a function of entrepreneurial collateral $q$. The left panel shows that the aggregate capital stock initially increases with $q$ but is constant after a critical value. The middle panel shows why this is the case: an increase in $q$ induces a shift in investment, raising unscreened capital at the expense of $H$-type capital. The reason is that higher values of $q$ relax the borrowing constraints of entrepreneurs, enabling them to expand unscreened investment. This expansion reduces the return to capital, however, and thus the benefits of screened investment. At some point, entrepreneurial collateral is high enough to sustain the unconstrained level of unscreened investment and, beyond this critical level, $q$ no longer affects the equilibrium capital stock. Finally, the right panel shows that the price of $H$-type capital, which captures the equilibrium value of the information, is decreasing in entrepreneurial collateral. This reflects the fact that an increase in entrepreneurial collateral reduces the need for screening and thus the value of information embedded in each unit of $H$-type capital.

Figure 1 summarizes the basic insight of our mechanism. There are two ways of investing 

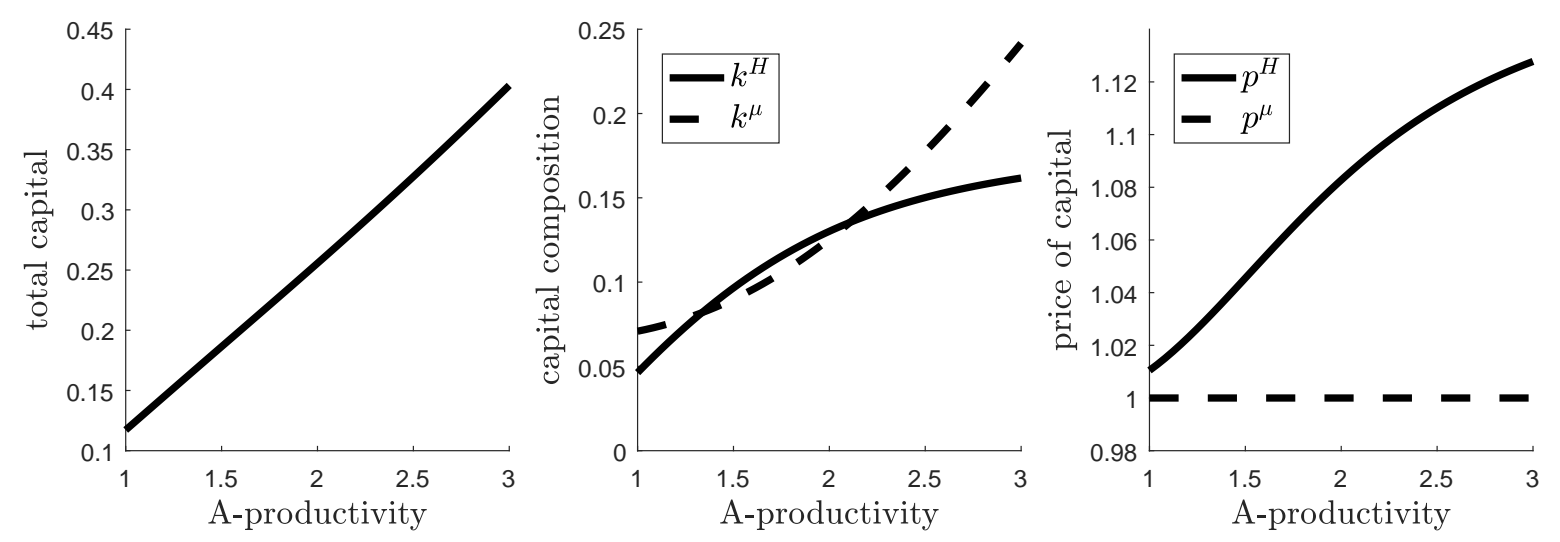

Figure 2: Effects of productivity when $\delta=1$. The figure depicts the equilibrium capital stock, its composition and capital prices, as a function of aggregate productivity $A$, in the economy with full depreciation. The parameter values used to produce the figures are provided in Appendix B.7.

in the economy: one is information-intensive, in the sense that it relies on costly screening to select units of $H$-type capital; the other one is not, in the sense that it relies on collateral and yields unscreened units of capital. In equilibrium, these two types of investment are substitutes. An increase in collateral shifts the composition of investment away from screened investment and, by doing so, enables the economy to save on screening costs. In a nutshell, collateral enables the economy to switch to a cheaper investment technology. As we shall see, however, this has important dynamic implications.

Before concluding, it is useful to contrast the effects of changes in entrepreneurial collateral and aggregate productivity. To this effect, Figure 2 depicts (for a given value of $q$ ) the equilibrium capital stock, its composition between $H$-type and unscreened capital, and the price of both types of capital, as a function of $A$. The left panel shows that, as expected, an increase in aggregate productivity raises the equilibrium capital stock. The middle panel shows, however, that this is due to an increase in both screened and unscreened capital. The reason is that higher productivity raises the expected return to all units of capital, increasing both entrepreneurs' willingness to invest in screened capital and their ability to invest in unscreened capital. Finally, the right panel shows that the price of $H$-type capital is monotonically increasing in productivity. This reflects the fact that, by raising the return to screened investment, an increase in productivity raises equilibrium screening and its cost, and thus the value of information embedded in each unit of $H$-type capital 14

\footnotetext{
${ }^{14}$ We have assumed throughout that the screening cost $\psi_{t}$ is unaffected by $A_{t}$. Thus, we think of fluctuations in $A_{t}$ as driven by terms-of-trade or sectoral shocks that do not affect the economy's information-gathering ability. If this were not the case and higher productivity also reduced screening costs, an increase in $A_{t}$ would induce an even higher increase in screened investment.
} 


\subsection{The dynamic model}

We now set $\delta<1$ and allow for shocks to entrepreneurial collateral and aggregate productivity, i.e., $q_{t} \in\{\underline{q}, \bar{q}\}$ and $A_{t} \in\{\underline{A}, \bar{A}\}$. If we focus on equilibria in which unscreened investment is always constrained by entrepreneurial net worth, then the dynamics of the economy are fully characterized by the following system of equations:

$$
\begin{gathered}
k_{t+1}^{\mu}=\frac{\rho}{\rho-\mu \cdot E_{t}\left\{\alpha \cdot A_{t+1} \cdot\left(k_{t+1}^{H}+k_{t+1}^{\mu}\right)^{\alpha-1}+1-\delta\right\}} \cdot q_{t}, \\
\frac{E_{t}\left\{r_{t+1}+(1-\delta) \cdot\left(1+\frac{\psi\left(s_{t+1}\right)}{\mu}\right)\right\}}{\rho}=1+\frac{\psi\left(s_{t}\right)}{\mu},
\end{gathered}
$$

and

$$
s_{t}=\max \left\{0, \frac{k_{t+1}^{H}-(1-\delta) \cdot k_{t}^{H}}{\mu}\right\},
$$

where $r_{t+1}$ is defined in Equation (3). The key difference with the "static" model is that the stock of screened capital $k_{t}^{H}$ now becomes a state variable. To see this, observe that - for

a given expected value of information in the future, $-k_{t+1}^{H}$ is increasing in $k_{t}^{H}$. Intuitively, a higher value of $k_{t}^{H}$ reduces equilibrium screening, as some of the information that is necessary to produce $H$-type capital is already embedded in pre-existing units: moreover, the ensuing fall in the cost of screening raises $k_{t+1}^{H}$ as well. In this sense, we can think of $k_{t}^{H}$ as embodying the economy's stock of information. But what is the dynamic behavior of this information? To understand this, we next study the equilibrium dynamics of our economy in response to unanticipated shocks, through the help of a simple phase diagram.

\subsection{1 "Slow-moving" information}

Let us suppose for now that the economy does not experience shocks, i.e. $q_{t}=q$ and $A_{t}=A$ for all $t$. Then, we can characterize both the steady state and the dynamic behavior of the economy with the help of a phase diagram in $k_{t}^{H}$ and $s_{t}$, as shown in Figure 3 . This figure depicts the following steady-state relationships:

$$
k^{H}=s \cdot \frac{\mu}{\delta},
$$

and

$$
\alpha \cdot A \cdot\left(k^{H}+k^{\mu}\left(k^{H}, q, A\right)\right)^{\alpha-1}=(\rho+\delta-1) \cdot\left(1+\frac{\psi(s)}{\mu}\right),
$$



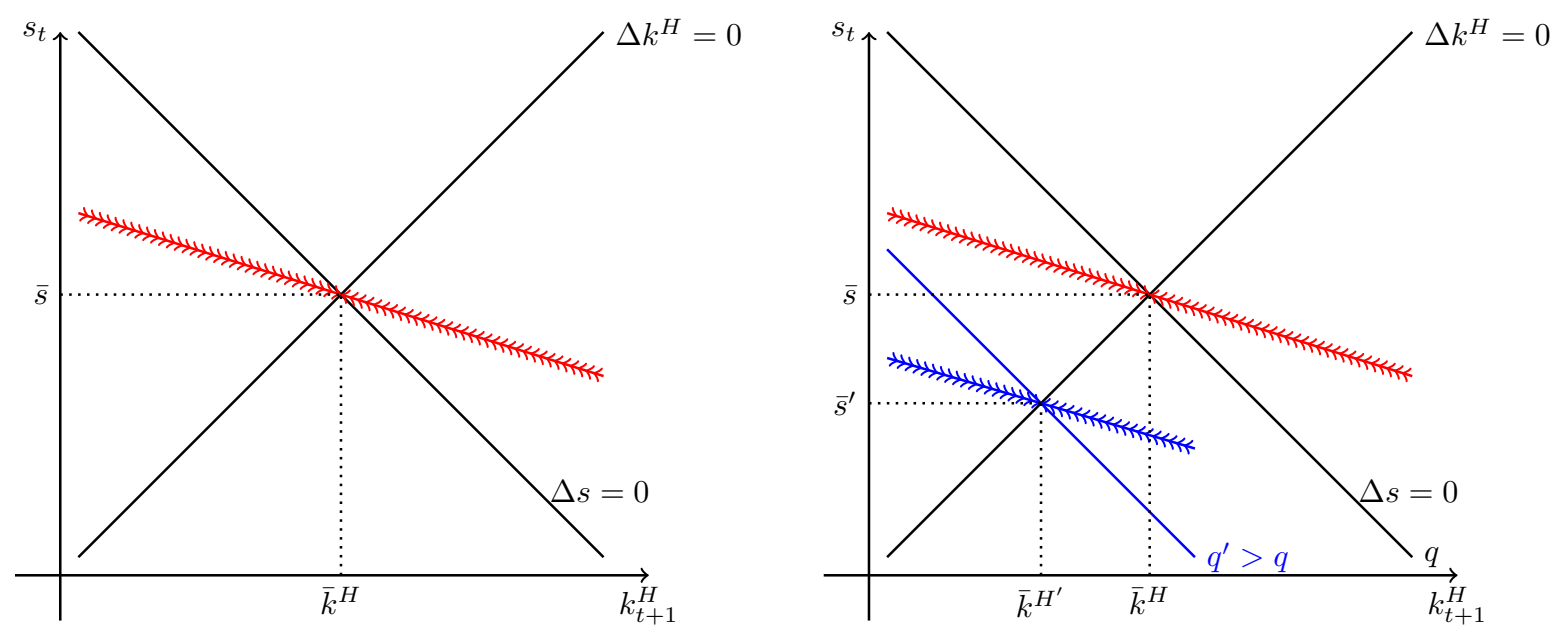

Figure 3: Information dynamics. The figure illustrates a phase diagram for the joint evolution of per period screening and the stock of $H$-type capital. In the left panel, the saddle path of the system is depicted in red. In the right panel, the saddle path is depicted in red prior to the unexpected shock to $q$, and in blue thereafter.

where $k^{\mu}\left(k^{H}, q, A\right)$ is implicitly defined by Equation (16), with $k^{\mu}$ increasing in $q$ but decreasing in $k^{H}$ (though less than one for one). Equation (19) represents the rate of per-period screening $s$ necessary to maintain $k^{H}$ units of $H$-type capital in steady state. Clearly, $s$ is increasing in $k^{H}$. Equation (20) instead represents the combinations of $s$ and $k^{H}$ that are consistent with profit maximization by entrepreneurs and market clearing. Here, $s$ and $k^{H}$ are negatively related because high levels of screening reduce the return to investment in $H$-type capital.

The left panel of Figure 3 depicts both loci in the $\left(k^{H}, s\right)$-space. Their intersection represents the steady state of the deterministic economy, which we denote by $\left(\bar{k}^{H}, \bar{s}\right)$. This system can be shown to be saddle-path stable, and its saddle path is also depicted in the figure. The dynamics of the system along the saddle path, as indicated by the arrows, depict the slow-moving nature of information. To see this, suppose the economy starts with an initial value $k_{0}^{H}<\bar{k}^{H}$. In this case, the economy needs to build up its stock of information and therefore requires a high level of screening $\left(s_{0}>\bar{s}\right)$ : along the transition, $k_{t}^{H}$ rises gradually towards $\bar{k}^{H}$ and $s_{t}$ falls gradually towards $\bar{s}$. Analogously, given an initial value $k_{0}^{H}>\bar{k}^{H}$, the economy must instead run down its stock of information and it therefore requires a low level of screening $\left(s_{0}<\bar{s}\right)$ : along the transition, $k_{t}^{H}$ falls towards $\bar{k}^{H}$ and $s_{t}$ rises towards $\bar{s}$.

The key takeaway of this dynamic model is that the economy cannot accumulate information instantaneously, as it would be too costly, but must instead do it over time. In this sense, information is "slow-moving." To further illustrate this adjustment, the right panel of Figure 3 depicts the response of the economy to a permanent and unexpected increase in $q$. Whereas the locus of Equation (19) is unaffected by this change, the locus of Equation (20) shifts down. 
The reason is that a higher value of $q$ raises unscreened capital, reducing the return to capital and thus the benefits of screening. As a result, screening collapses on impact as the economy jumps to the new saddle path: at the new, higher level of entrepreneurial collateral, it is simply not worth maintaining the pre-existing stock of $H$-type capital. Along this new saddle path, the economy gradually transitions towards the new steady state, which has both lower $k^{H}$ and $s$ relative to the original steady state.

Thus, as in the static model, the economy responds to an increase in $q$ by reducing its information production. Crucially, however, now the depletion of information (or its accumulation) occurs gradually over time, as screened capital transitions slowly to its new steady state. As we will see shortly, such slow-moving information dynamics have important bearing on the equilibrium dynamics of boom-bust cycles.

Finally, it is worth noting that an increase in aggregate productivity as measured by $A$ would have the opposite effect to that of an increase in $q$, as it would induce an upward shift of the locus defined by Equation 20, thereby raising the steady-state values of $k^{H}$ and $s$. Therefore, just as in the static model, increases in entrepreneurial collateral deplete information production whereas increases in aggregate productivity foster it.

\subsubsection{Boom-bust episodes}

We are now ready to study the behavior of the economy in response to fluctuations in collateral values, taking into account that agents are forward-looking and fully aware of the stochastic nature of the economy. To do so, let us suppose that the economy fluctuates between low- and high-collateral states, according to a Markov process with transition probabilities $P\left(q_{t}=\bar{q} \mid q_{t-1}=\underline{q}\right) \in\left(0, \frac{1}{2}\right)$ and $P\left(q_{t}=\underline{q} \mid q_{t-1}=\bar{q}\right) \in\left(0, \frac{1}{2}\right)$. We assume that $\bar{q}>\underline{q}$ and both are low enough so that entrepreneurs are constrained in both states. Although we provide an interpretation for the source of fluctuations in $q$ in the next section, it suffices for now to think about an economy that experiences boom-bust episodes driven by exogenous shocks to the value of collateral.

Figure 4 illustrates the behavior of an economy that is initially in the low-collateral state but then transitions to the high-collateral state. On impact, the economy experiences an investment boom and a shift in the composition of investment: unscreened investment increases at the expense of screened investment. As the high-collateral state persists, the economy gradually converges to a new steady state with a higher total capital stock but with a lower stock of screened capital. In other words, and as discussed in the previous section, the economy depletes its stock of information during the high-collateral state.

What happens when the boom ends and the economy returns to the low-collateral state? 

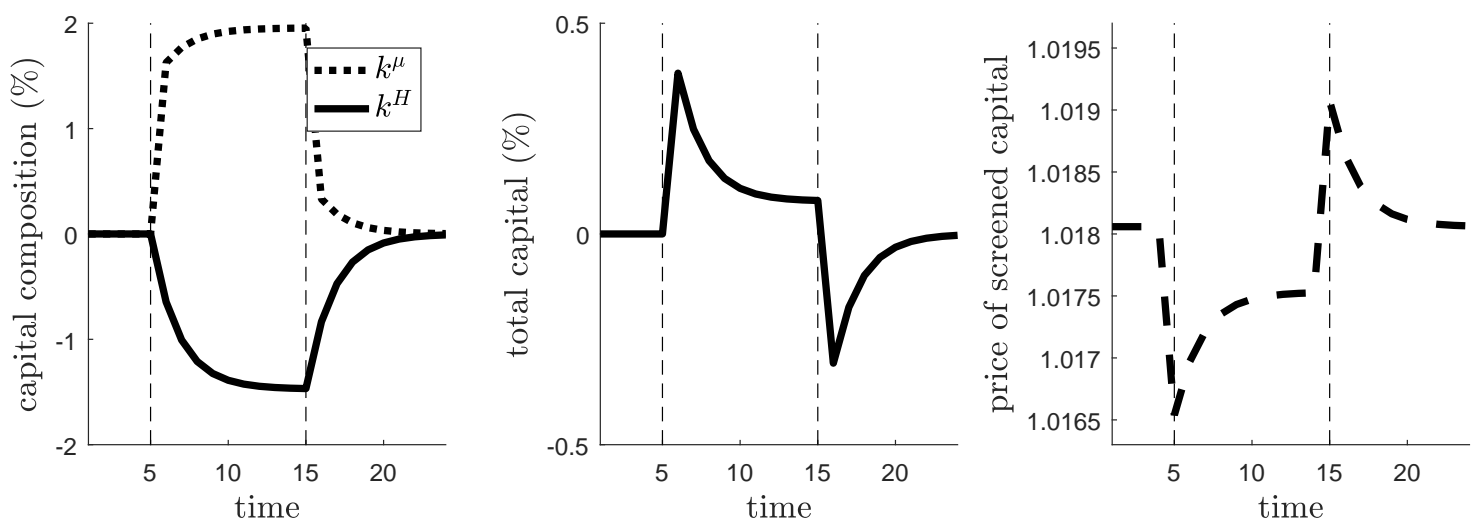

Figure 4: Collateral boom-bust episode. The figure depicts the equilibrium evolution of the capital stock, its composition and capital prices throughout a collateral boom-bust episode. Collateral values are $q_{t}=\underline{q}$ before period 5 and after period 15 , and $q_{t}=\bar{q}>q$ between periods 5 and 15 . The variables are expressed in percentage deviation from their low-collateral steady state value, except for the price of screened capital. The parameter values used to produce the figures are provided in Appendix B.7

At this point, young entrepreneurs do not have enough collateral to sustain the stock of unscreened capital that was built during the boom. Thus, they shift their investment towards $H$-type capital, but its stock was depleted during the boom and there is not enough of it to go around. This scarcity of screened capital translates into both a higher price, which can be interpreted as a "flight to information," and a spike in the cost of screening. The high cost of screening, in turn, limits the economy's ability to expand screened capital quickly. Unable to maintain the stock of unscreened capital or to quickly rebuild the stock of screened capital, the economy temporarily undershoots its new steady-state level of output. Thus, the depletion of information during the boom amplifies the fall in output when the bust comes. Moreover, as Figure 5 shows, because longer booms lead to more information depletion, they also tend to end in deeper busts or "crises."

Figures 4 and 5 thus summarize the key properties of collateral-driven booms. As long as they last, collateral booms raise the economy's capital stock and output, but they deplete its stock of information embedded in screened capital. As a result, when the boom comes to an end, it triggers a decline in economic activity, which is stronger and longer-lasting the more time the economy has spent in the boom.

It is again instructive to contrast the boom-bust episodes driven by collateral values with those driven by productivity shocks. To this effect, Figure 6 depicts the evolution of an economy that (for given value of $q$ ) transitions between low- and high-productivity states. In this case, both types of capital increase during the boom. As a result, when the economy transitions back to the low-productivity state, it does so with a relatively high stock of screened 

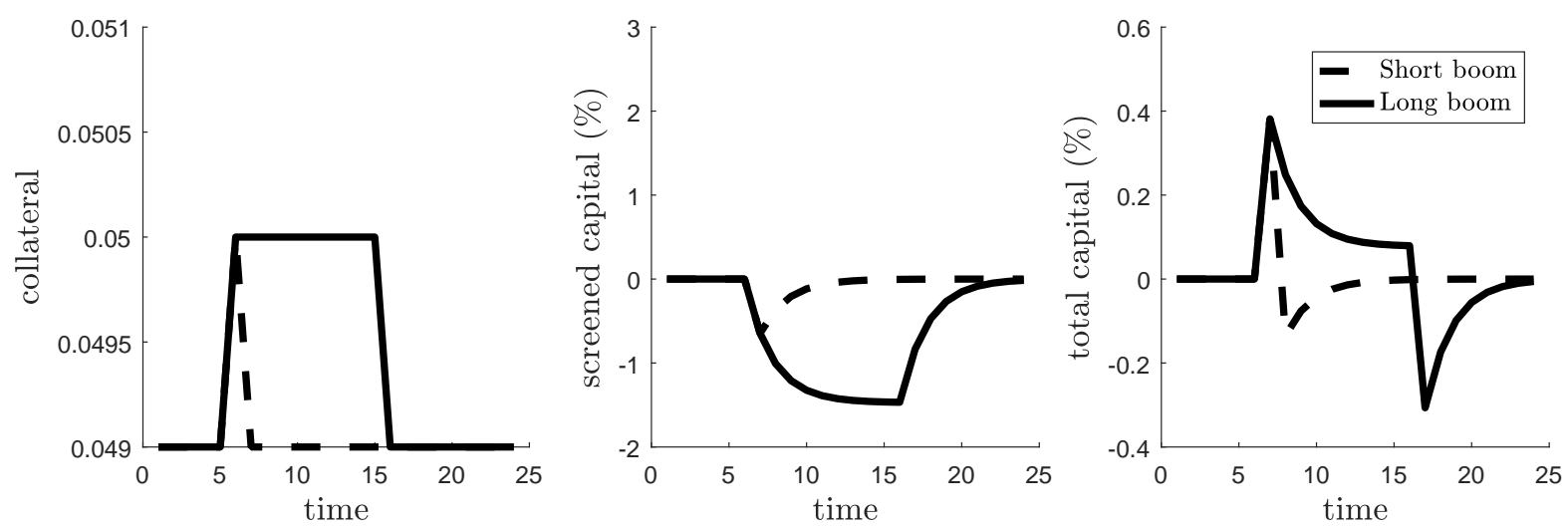

Figure 5: Longer booms, larger busts. The figure depicts the equilibrium evolution of the total capital and $H$-type capital throughout collateral boom-bust episodes of two different durations: one lasts from period 5 to period 7, whereas the other lasts from period 5 to period 15 . The variables are expressed in percentage deviation from their low-collateral steady state value, except for collateral. The parameter values used to produce the figures are provided in Appendix B.7.

capital. Despite the fall in productivity, this relative abundance of screened capital "cushions" the economy's transition to the new steady state.
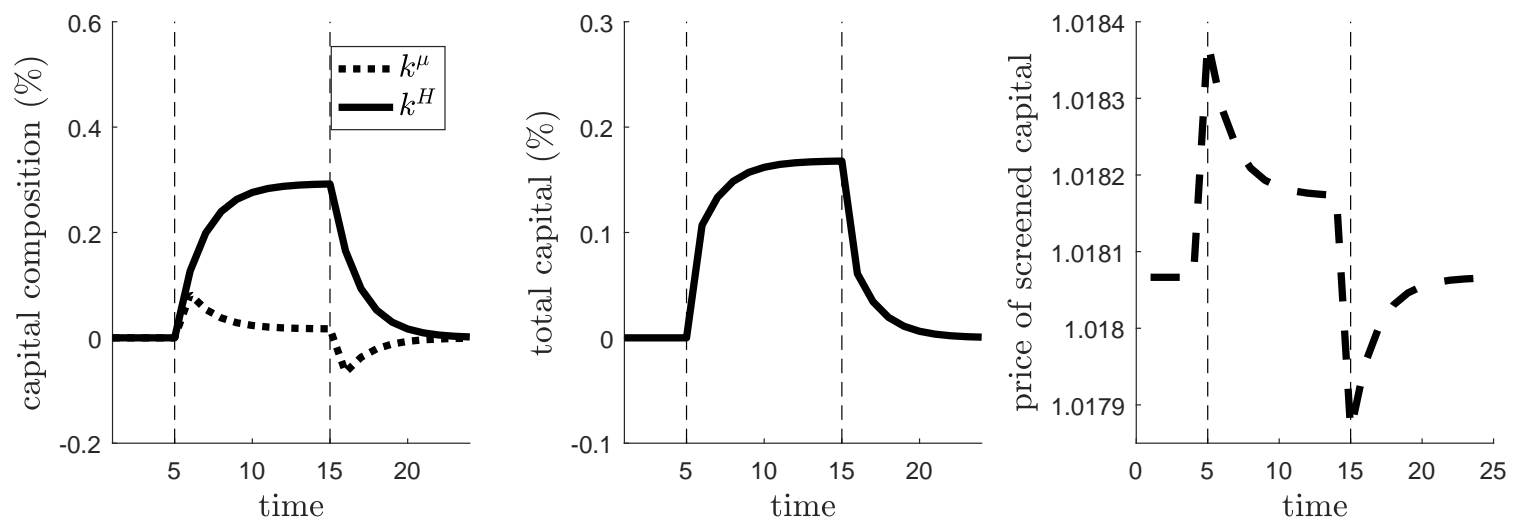

Figure 6: Productivity boom-bust episode. The figure depicts the equilibrium evolution of the capital stock, its composition and capital prices throughout a productivity boom-bust episode. Aggregate TFP is $A_{t}=\underline{A}$ before period 5 and after period 15 , and $A_{t}=\bar{A}>\underline{A}$ between periods 5 and 15 . The variables are expressed in percentage deviation from their low-productivity steady state value, except for the price of screened capital. The parameter values used to produce the figures are provided in Appendix B.7

\subsection{Discussion}

Our theory is based on a simple premise: some types of investment enable entrepreneurs to divert resources for private consumption. To break even, lenders protect themselves against such diversion either by asking entrepreneurs for collateral or by engaging in costly screening 
of entrepreneurs' projects. The key insight of the model is that the equilibrium amount of screening depends on the availability of collateral. During collateral booms, the economy naturally relies less on screening and more on collateralization. But this depletes the stock of information embedded in screened projects. Because information is slow-moving, moreover, the end of a collateral boom is accompanied by a deep bust and a slow recovery.

The main implications of the theory are broadly in line with several strands of stylized evidence. First, there is ample evidence that investment is increasing in the value of collateral (e.g. Chaney et al. (2012)). Second, there is also evidence that the quality of lenders' information on borrowers is lower in good times (Becker et al., 2016; Lisowsky et al., 2017), which is consistent with information depletion during booms ${ }^{15}$ At a more aggregate level, the theory is consistent with the empirical finding that not all credit booms are alike: in particular, credit booms that are accompanied by house price booms (Richter et al., 2017) and that are characterized by low productivity growth (Gorton and Ordoñez, 2016) are more likely to end in crises.

Going beyond these broad implications of the theory, we can distill the following main predictions on the relationship between entrepreneurial collateral, investment, and information generation:

- Prediction 1: investment is increasing in entrepreneurial collateral. This prediction, which is common to many models with financial frictions, follows directly from our framework whenever the borrowing constraint on unscreened investment is binding.

- Prediction 2: the share of investment in unscreened capital is increasing in entrepreneurial collateral.

- Prediction 3: falls in entrepreneurial collateral are accompanied by a reduction in investment and, all else equal, the magnitude of this reduction is increasing in the economy's share of unscreened capital.

In Section 6, we test these predictions on US firm-level data. Before doing so, however, Sections 4 and 5 address a number of important conceptual questions. How do we interpret collateral shocks, which are a key driver of the story? How robust are the theory's main findings to alternative specifications of the environment? And, most importantly, what are the theory's normative implications? Although these sections provide further insights into the theory, less patient readers may skip them and go straight to the empirical results.

\footnotetext{
${ }^{15}$ Using Swedish data, for instance, Becker et al. (2016) find that banks are less able to predict the credit quality of borrowers in good times. Lisowsky et al. (2017), in turn, show that banks significantly reduced their collection of audited financial statements from construction firms during the US housing boom before 2008.
} 


\section{Additional considerations}

This section discusses some economic interpretations and extensions of our baseline model. Specifically, we provide an interpretation of collateral shocks and explore two simple extensions of our baseline model. The first extension allows for differences in productivity between $H$ - and $L$-type capital, thereby generating dispersion in measured productivity, whereas the second one introduces fire sales into the model.

\subsection{Interpreting collateral shocks}

Up to now, we have treated fluctuations in the value of collateral $q_{t}$ as fully exogenous, without specifying their origin. From an economic standpoint, these fluctuations reflect changes in the net worth or collateral of entrepreneurs that are orthogonal to their investment and production opportunities. In this section, we provide two interpretations/micro-foundations for such fluctuations, one that is driven by fundamentals and the other that results from over-valuations or asset price bubbles.

In the first and simplest interpretation, each tree is a unit of land or some other "natural resource" that produces a stochastic fruit $n_{t}$ in period $t$. Young entrepreneurs of generation $t$ are endowed with land that they can sell to savers at a price:

$$
q_{t}=E_{t}\left\{\sum_{s>t} \frac{n_{s}}{\rho^{s-t}}\right\}
$$

where we assume that $\rho>1$ and impose the "no-bubbles" condition to focus on fundamental equilibria. Note that the savers' rate of discount is the international interest rate $\rho$, as they can always purchase land (or lend against it) by borrowing from the international capital market at rate $\rho$. Thus, fluctuations in $q_{t}$ can be interpreted as natural resource shocks, which affect the net worth of entrepreneurs but not the productivity of investment or production.

In the second, subtler interpretation, $q_{t}$ reflects the existence of asset bubbles. Consider a slightly modified version of our economy in which production is organized in firms. Firms contain units of capital that can be created by young entrepreneurs at zero cost.

Under certain conditions, it is easy to show that this modified economy admits two types of equilibria: fundamental equilibria, in which the price of a firm equals the cost of replacing its capital stock, and bubbly equilibria, in which the price of a firm exceeds the cost of replacing its capital stock. 16 Formally, if we use $J_{t}$ to denote the set of firms that are active in period

\footnotetext{
${ }^{16}$ See Martin and Ventura (2018) for a discussion of these conditions in a closely related framework.
} 
$t$, we can write the market price of firm $j \in J_{t}$ as:

$$
\nu_{j t}=(1-\delta) \cdot\left(p_{t}^{\mu} \cdot k_{j t}^{\mu}+p_{t}^{H} \cdot k_{j t}^{H}\right)+b_{j t},
$$

where $k_{j t}^{\mu}$ and $k_{j t}^{H}$ respectively denote the units of unscreened and $H$-type capital owned by firm $j$ in period $t$, and $b_{j t}$ denotes the value of the bubble attached to firm $j$.

In a fundamental equilibrium, $b_{j t}=0$ for all $j \in J_{t}$ and a firm's price is exactly equal to the value of the capital stock that it contains. In a bubbly equilibrium, instead, $b_{j t}>0$ for some $j \in J_{t}$, and the price of some firms exceeds the value of the capital stock that they contain. Given the international interest rate $\rho$ and firm prices in Equation $(22), b_{j t}>0$ in equilibrium if and only if:

$$
\rho=\frac{E_{t} b_{j t+1}}{b_{j t}} .
$$

Equation (23) says that the expected growth rate of bubbles must equal the interest rate. If this condition was not satisfied with equality, the demand for firms by young entrepreneurs would be either excessive or insufficient. In any bubbly equilibrium, the evolution of $b_{j t}$ is driven by market psychology or investor sentiment.

It is relatively straightforward to show that, together with a process of $b_{j t}$ that satisfies Equation (23), Equations (16)-(18) can be interpreted as a bubbly equilibrium in which $q_{t}$ reflects the bubbles attached to newly created firms at time $t$. According to this interpretation, fluctuations in $q_{t}$ reflect changes in the market psychology that drives these bubbles, which in turn affect entrepreneurial net worth. When this component grows, the market is more willing to lend against the value of new firms and entrepreneurs can use this additional borrowing to expand investment. When this component shrinks (or disappears!), the market is less willing to lend against the bubbly component of new firms and entrepreneurial borrowing and investment falls. Our main result can thus be interpreted as an additional, and so far unexplored, cost of bubbles: they raise investment but, by providing collateral, also shift its composition away from screened capital. This means that bubbly episodes are characterized by a depletion of screened capital and, as in Section 3, the bursting of bubbles is accompanied by an undershooting of the capital stock and output.

\subsection{Collateral booms and "misallocation"}

There has been substantial debate recently regarding the effects of credit booms on the allocation of resources. In particular, there is a growing view that credit booms are associated with an increase in "misallocation" of resources. Following Hsieh and Klenow (2009), misallocation is typically measured as the dispersion of TFP (more precisely, revenue TFP) - 
normalized by average productivity - across plants or firms in a given industry. In an ideal world, resources would flow from less to more productive firms/plants to eliminate any such dispersion. If this is not the case, the logic goes, there must be frictions that prevent the efficient allocation of resources. Recently, García-Santana et al. (2016) and Gopinath et al. (2017) have documented a significant increase in misallocation during the Spanish credit boom of the early 2000's, which has been broadly interpreted as an indication that the allocation of resources is somehow distorted during episodes of rapid credit growth.

Our model offers an alternative interpretation of this evidence. To see this, it is best to focus on the static version of the model (i.e., $\delta=1$ ), assume that productivity is constant (i.e. $A_{t}=A$ for all $t$ ), and modify it along one key dimension: besides their different pledgeability to outside creditors, units of high-quality capital are also more productive than low-quality capital. In particular, we assume that - for productive purposes - each unit of low-quality capital is equivalent to $\lambda<1$ units of high-quality capital. With these modifications, the equilibrium of the static model is essentially unchanged relative to Equations (14) and (15), where

$$
k_{t+1}^{\mu}=\min \left\{\frac{\rho}{\rho-\mu \cdot E_{t} r_{t+1}} \cdot q_{t}, \max \left\{0,\left[\left(\frac{A \cdot \alpha \cdot \tilde{\lambda}}{\rho}\right)^{\frac{1}{1-\alpha}}-k_{t+1}^{H}\right] \frac{1}{\widetilde{\lambda}}\right\}\right\},
$$

where $\tilde{\lambda}=\mu+(1-\mu) \cdot \lambda$, which reflects the fact that unscreened investment is now less productive, whereas the evolution of $k_{t}^{H}$ is still governed by 15 .

What does the variance of TFP (i.e., "misallocation") look like in this extended model, and how does it evolve during a collateral-driven credit boom? Answering this question requires taking a stance on what the unit of observation is. Since firms are a veil in our constant-returns-to-scale environment, we can consider the case in which each unit of capital is operated separately as an independent plant or business unit. In such a case, misallocation can be expressed as follows:

$$
V A R_{T F P, t}=\frac{k_{t}^{H}+\mu \cdot k_{t}^{\mu}}{k_{t}^{H}+k_{t}^{\mu}} \cdot\left(\frac{A}{\bar{A}_{t}}-1\right)^{2}+\frac{(1-\mu) \cdot k_{t}^{\mu}}{k_{t}^{H}+k_{t}^{\mu}} \cdot\left(\frac{\lambda^{\alpha} \cdot A}{\bar{A}_{t}}-1\right)^{2}
$$

where $\bar{A}_{t}$ denotes the average of measured TFP. This expression has a very natural interpretation. Of all the units of capital in the economy, $k_{t}^{H}+\mu \cdot k_{t}^{\mu}$ are of $H$-type and for these units measured TFP equals $A>\bar{A}_{t}$. The remaining $(1-\mu) \cdot k_{t}^{\mu}$ units are of $L$-type and for these units measured TFP equals $\lambda^{\alpha} \cdot A<\bar{A}_{t}$.

Although we relegate the derivation to Appendix B.3, misallocation in this economy depends only on the ratio of screened to unscreened capital, $k_{t}^{H} / k_{t}^{\mu}$. Specifically, misallocation is 

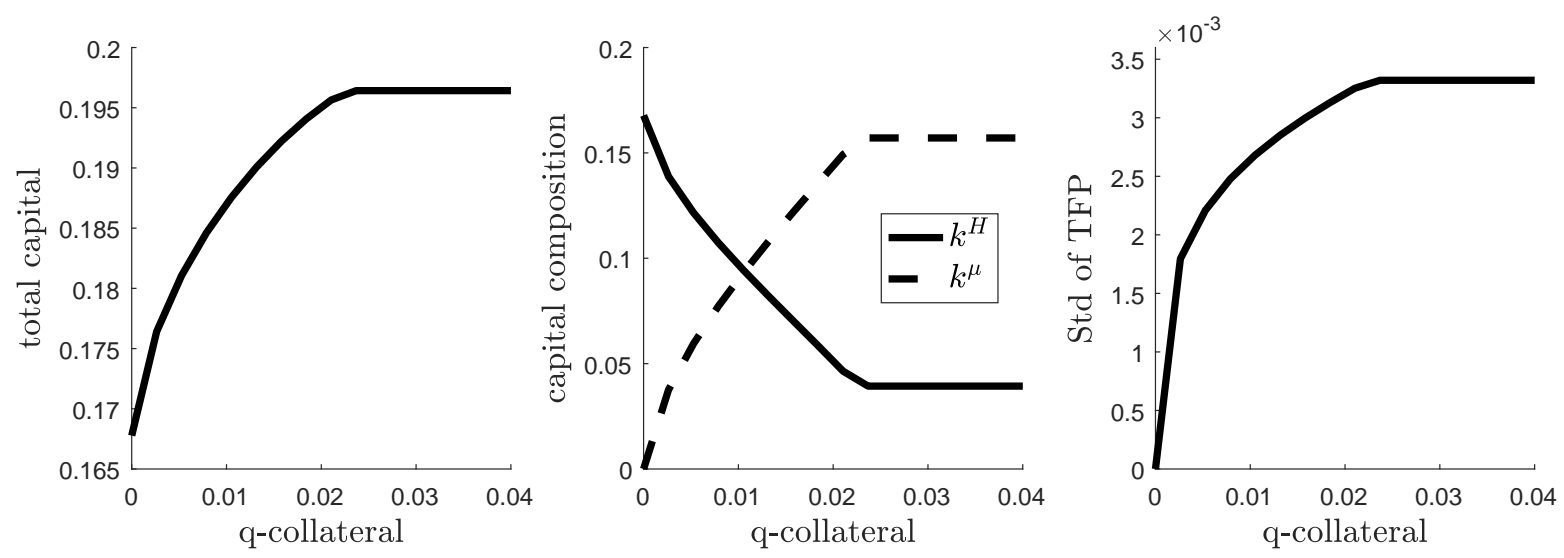

Figure 7: Collateral values and misallocation. The figure depicts the equilibrium capital stock and its composition, and the standard deviation of productivity, as a function of collateral $q$, in the economy with full depreciation. The parameter values used to produce the figures are provided in Appendix B.7

decreasing in this ratio (and thus increasing in $q_{t}$ ) if and only if

$$
\frac{k_{t}^{H}}{k_{t}^{\mu}}>\lambda^{\alpha} \cdot(1-\mu)-\mu .
$$

This condition has a natural economic interpretation, which can be phrased as follows: an increase in $k_{t}^{H} / k_{t}^{\mu}$ reduces misallocation if and only if the stock of high-quality capital in the economy exceeds the (productivity weighted) stock of low-quality capital. This always holds if $\mu>\lambda^{\alpha} /\left(1+\lambda^{\alpha}\right)$, and it requires $k_{t}^{H} / k_{t}^{\mu}$ to exceed a certain threshold otherwise.

Figure 7 illustrates, for our baseline parametrization, the evolution of measured misallocation as a function of $q_{t}$. In this parametrization, condition (26) always holds. When $q_{t}=0$, all investment is screened and there is no misallocation: ultimately, the economy has only high-quality capital. As $q_{t}$ increases and the composition of the capital stock shifts towards unscreened capital (i.e., $k_{t}^{H} / k_{t}^{\mu}$ falls), misallocation rises. Simply put, agents reduce their screening before investing and this leads to higher investment in low-quality capital. When $q$ is large enough, entrepreneurs become unconstrained, and their investment decisions and thus misallocation no longer depends on collateral values.

We can easily extend this static example to the fully dynamic economy to show how collateral-driven booms can be accompanied by rising misallocation. In this way, the model is consistent with the empirical evidence outlined above. It is also consistent, moreover, with the narrative that is commonly used to rationalize this evidence: during booms, credit ends up being allocated to low-quality projects. In our model, however, this is not necessarily inefficient. It is true that agents reduce their screening and therefore make their investment 
decisions with less information. But generating this information is costly! In other words, the availability of collateral enables the economy to switch to a cheaper investment technology, albeit one that leads to more disperse outcomes.

\subsection{Irreversibilities and fire-sales}

Our baseline model assumes that capital is perfectly reversible. Although convenient, this assumption has a very stark (and counterfactual) implication. When a collateral boom ends, young entrepreneurs can no longer borrow to finance unscreened investment: unable to find buyers for their stock of unscreened capital, old entrepreneurs simply consume part of it. As a result, the bust is fully absorbed by the quantity of unscreened capital and not by its price, which cannot fall below one. And, since the price of screened capital rises alongside screening activity, a collateral bust is actually accompanied by an increase in the average price of capital!

This conclusion of our baseline model may strike the reader as problematic. Crises are typically characterized by falling asset prices, although some assets - especially those perceived as safe - may see their prices rise as agents "fly to quality." This counterfactual implication of our model for the behavior of asset prices can be addressed through a slight modification of the framework, however, which captures irreversibilities in capital formation.

Suppose that, at any point in time, a unit of capital can be liquidated and converted into $\chi \in(0,1)$ units of consumption. This means that it is costly to reverse capital, since a fraction $1-\chi$ of each unit is lost in the process. A broader interpretation of this assumption is that there are other agents in the economy that can use capital, albeit less productively than entrepreneurs. Under this interpretation, the magnitude of $1-\chi$ captures the inefficiencies associated with "fire-sales" of capital during periods of systemic distress (Shleifer and Vishny, 2011). For simplicity, our baseline model has focused on the case of $\chi=1$.

This assumption has a key implication for our model: whenever the economy liquidates screened or unscreened capital, i.e., $k_{t+1}^{j} \leq(1-\delta) \cdot k_{t}^{j}$ for $j \in\{H, \mu\}$, the corresponding price will be depressed, i.e., $p_{t}^{j} \in[\chi, 1]$. Except for this modification to capital prices, the characterization of equilibrium is basically as before. Equations (46)-(51) in the Appendix provide a formal description of the equilibrium.

Figure 8 illustrates the workings of this modified model by simulating a collateral boombust episode. We use the same parametrization as in the baseline model, except that we now set $\chi=0.9$ (instead of $\chi=1$ ) therefore allowing for a maximum fall of ten percent in capital prices, and we feed a larger shock to collateral values to ensure that fire-sales are triggered in the low-collateral state. The evolution of the total capital stock, as well as its composition between screened and unscreened capital, is qualitatively similar to that of our baseline model. 

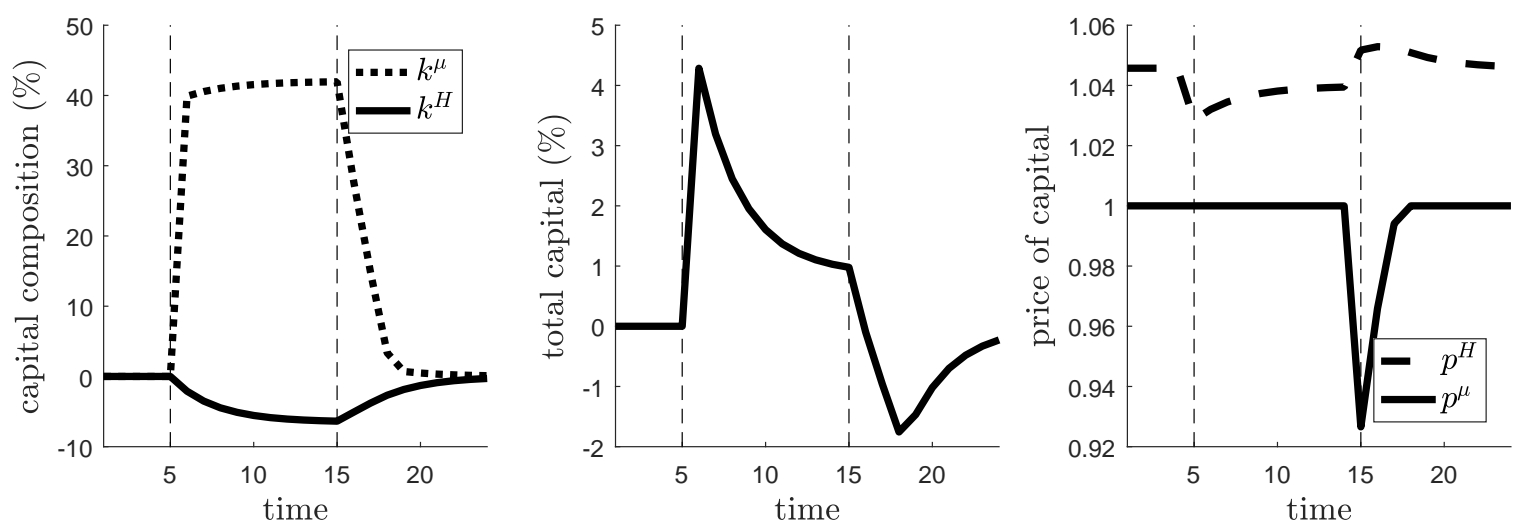

Figure 8: Collateral boom-bust episode with $\chi<1$. The figure depicts the equilibrium evolution of the capital stock, its composition and capital prices throughout a collateral boom-bust episode. Collateral values are $q_{t}=q$ before period 5 and after period 15 , and $q_{t}=\bar{q}>q$ between periods 5 and 15 . The variables are expressed in percentage deviation from their low-collateral steady state value, except for the price of screened capital. The parameter values used to produce the figures are provided in Appendix B.7.

The main difference is that, during the bust, the fall in unscreened capital is absorbed by a decline in its price. As in the baseline model, the fall in collateral values means that young entrepreneurs are unable to maintain the stock of unscreened capital. But this now leads to a fire-sale of unscreened capital and to a decline in its price, which relaxes the borrowing constraint of entrepreneurs and absorbs the impact of the shock on the capital stock.

Note also that, while the price of unscreened capital falls, the price of screened capital rises. The reason is that the information attached to screened units of capital is particularly valuable during the bust. Thus, the simulation shows that one of the main insights of the baseline model is robust to the inclusion of irreversibilities: the value of information is countercyclical with respect to collateral values, and the relative value of screened assets is highest during collateral busts, when collateral is most scarce.

\section{$5 \quad$ Is there too little information?}

One of the main insights of Section 3 is that, during collateral-driven boom-bust cycles, the effects of the bust are magnified due to the depletion of information that takes place during the boom. It may be tempting to conclude that this depletion of information is inefficient, in the sense that the amount of information produced in equilibrium is inefficiently low. In this section, we show that such a conclusion is unwarranted in our baseline model. Since the market for capital is undistorted and agents are forward-looking, market prices accurately reflect the value of information: thus, even at the peak of a collateral-driven boom, agents effectively anticipate the benefits of owning screened capital in the event that the bust materializes. If 
anything, due to a pecuniary externality that arises because the marginal product of capital affects borrowing constraints, the information produced in equilibrium is inefficiently high!

To show this, we consider the problem of a social planner whose objective is to maximize the present value of aggregate consumption net of screening costs, discounted at the interest rate $\rho$. Since agents' preferences are linear, this is equivalent to the maximization of social welfare, where the welfare of future generations is discounted at rate $\rho\left[{ }^{17}\right.$ We make a set of assumptions on what the planner can do in order not to give her undue advantage over the market. First, we assume that $\rho>1$ : this implies that the economy is dynamically efficient and eliminates gains from inter-generational transfers. Second, we assume that the planner is subject to the same borrowing constraints as private agents: thus, the planner can only finance unscreened investment by posting trees and the returns to $H$-type capital as collateral. Finally, we focus on parameter values for which borrowing constraints bind at the planner's solution: as in the competitive equilibrium, this requires $q_{t}$ to be low enough for all $t$.

Under these assumptions, the planner's problem reduces to choosing a sequence of screening policies, $\left\{s_{t}\right\}$, which determine the evolution of $H$-type capital and - through the borrowing constraints - also the evolution of unscreened capital 18 This problem can be expressed recursively as follows:

$$
\begin{aligned}
V\left(k_{t}^{H}, k_{t}^{\mu}, q_{t}, A_{t}\right) & =\max _{s_{t}, k_{t+1}^{\mu}, k_{t+1}^{H}} A_{t} \cdot k_{t}^{\alpha}+(1-\delta) \cdot k_{t}-k_{t+1}-\int_{0}^{s t} \psi(x) d x+q_{t} \\
& +\rho^{-1} \cdot E_{t} V\left(k_{t+1}^{H}, k_{t+1}^{\mu}, q_{t+1}, A_{t+1}\right)
\end{aligned}
$$

subject to the following set of constraints:

$$
\begin{gathered}
k_{t+1}=k_{t+1}^{\mu}+k_{t+1}^{H}, \\
s_{t}=\mu^{-1} \cdot \max \left\{0, k_{t+1}^{H}-(1-\delta) k_{t}^{H}\right\}, \\
k_{t+1}^{\mu}=\frac{\rho}{\rho-\mu \cdot E_{t}\left\{\alpha A_{t+1}\left(k_{t+1}^{\mu}+k_{t+1}^{H}\right)^{\alpha-1}+1-\delta\right\}} \cdot q_{t},
\end{gathered}
$$

where $V$ is the planner's value function, which depends on the economy's state variables, i.e., the stock of screened and unscreened capital, the value of collateral and aggregate productivity. The planner's per period return is simply given by the total output of the economy net of investment in physical capital and net of the screening costs of the experts (see derivation in Appendix B.4 plus the value of collateral. Constraints (28)-(30) respectively state that

\footnotetext{
${ }^{17}$ For simplicity, we abstract from distributional effects within a given a generation.

${ }^{18}$ Just as the entrepreneurs, the planner will never find it optimal to invest in a unit of capital if it is screened and turns out to be $L$-type.
} 
the aggregate capital stock is equal to the sum of $H$-type and unscreened capital; that the evolution of $H$-type capital must be consistent with screening activity; and that investment in unscreened capital must satisfy the borrowing constraint.

The borrowing constraint in Equation (30) plays a key role. It implicitly defines the stock of unscreened capital as a decreasing function of the stock of $H$-type capital, i.e. $k_{t+1}^{\mu}=k^{\mu}\left(k_{t+1}^{H}, q_{t}, A_{t}\right)$, with $\partial k^{\mu}\left(k_{t+1}^{H}, q_{t}, A_{t}\right) / \partial k_{t+1}^{H}<0$. This reflects the fact that an additional unit of screened investment reduces the marginal product of capital, thereby tightening borrowing constraints and crowding out unscreened investment. In the laissez-faire equilibrium, entrepreneurs do not internalize this relationship because they take the marginal product as given. But the planner does, and the first-order conditions to her problem yield:

$$
\begin{aligned}
1+\frac{\psi\left(s_{t}\right)}{\mu} & =\frac{E_{t}\left\{\alpha A_{t+1} k_{t+1}^{\alpha-1}+(1-\delta) \cdot\left(1+\frac{\psi\left(s_{t+1}\right)}{\mu}\right)\right\}}{\rho} \\
& +\left(\frac{E_{t}\left\{\alpha A_{t+1} k_{t+1}^{\alpha-1}+1-\delta\right\}}{\rho}-1\right) \cdot \frac{\partial k^{\mu}\left(k_{t+1}^{H}, q_{t}, A_{t}\right)}{\partial k_{t+1}^{H}}
\end{aligned}
$$

Together with (28)-(30), Equation (31) characterizes the solution to the planner's problem.

Equation (31) illustrates the key difference between the planner's solution and the competitive equilibrium. At the competitive equilibrium, market clearing and optimization require that the market value of a unit of screened capital, i.e., $1+\frac{\psi\left(s_{t}\right)}{\mu}$, equals its expected discounted return. In contrast, the planner's optimality condition has an additional negative term in the right-hand-side of Equation (31), because she understands that each unit of screened investment crowds out unscreened capital. And, insofar as borrowing constraints bind, the expected return to unscreened investment, $E_{t}\left\{\alpha A_{t+1} k_{t+1}^{\alpha-1}+1-\delta\right\}$, exceeds the interest rate, $\rho$, and this crowding out leads to a first-order welfare loss. This pecuniary externality is akin to those identified in the macro-finance literature (Caballero and Krishnamurthy, 2003; Lorenzoni, 2008; Dávila and Korinek, 2017), but it arises here because investment in one technology (screened) excessively restricts investment in the other one (unscreened).

The planner's allocations can be decentralized as a competitive equilibrium through a sequence of Pigouvian taxes $\left\{\tau_{t}\right\}$ on each unit of screened investment, with revenues rebated in lump sum fashion to the savers. Letting $\left\{s_{t}^{*}, k_{t+1}^{*}, k_{t+1}^{H *}\right\}$ denote the planner allocation, the sequence of taxes that implements these can be shown to satisfy:

$$
\tau_{t}=-\left(\frac{E_{t}\left\{\alpha A_{t+1} k_{t+1}^{* \alpha-1}+1-\delta\right\}}{\rho}-1\right) \cdot \frac{\partial k^{\mu}\left(k_{t+1}^{H *}, q_{t}, A_{t}\right)}{\partial k_{t+1}^{H}}+\frac{1-\delta}{\rho} \cdot E_{t} \tau_{t+1}
$$

The first term on the right-hand side of Equation (32) reflects the pecuniary externality the 


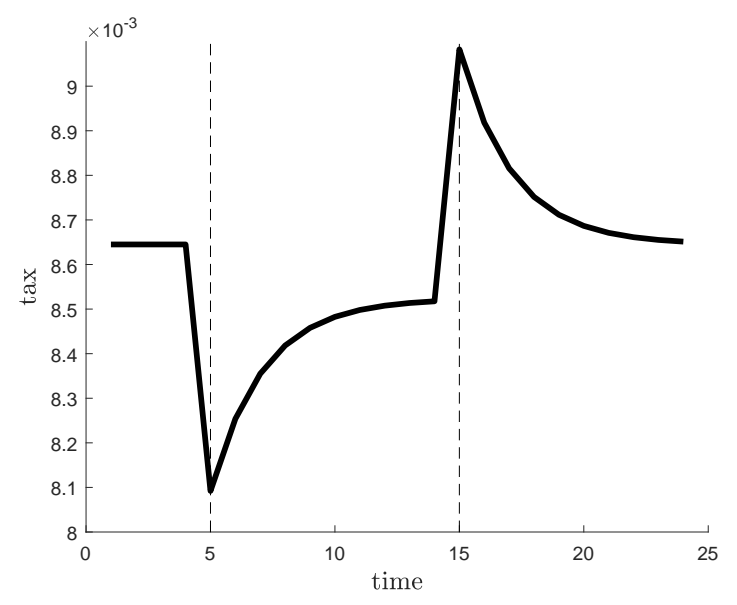

Figure 9: Optimal tax during a collateral boom-bust episode. The figure depicts the value of the tax $\tau_{t}$ during the collateral boom-bust episode that is depicted in Figure 4 . The parameter values used to produce the figures are provided in Appendix B.7.

planner wants to correct: by taxing screened investment, the planner reduces it relative to the competitive equilibrium. The second term reflects instead an intertemporal relationship between the planner's interventions at different points in time. In particular, the expected tax in period $t+1$ raises the price of screened capital in that period and, thus, the expected capital gains of screened investment in period $t$. In order to neutralize these gains, the planner must raise the tax $\tau_{t}$ beyond what would be warranted by the pecuniary externality alone.

Figure 9 illustrates the evolution of the $\operatorname{tax} \tau_{t}$, which captures the degree of inefficiency of competitive equilibrium, over the collateral-driven boom-bust cycle studied in Section 3 and depicted in Figure 4. There are two main takeaways from the figure. First, the tax is always positive because - due to the crowding-out effect of sceened investment - information production is excessive in the laissez faire equilibrium. Second, in the simulation, the tax is countercyclical as it is primarily driven by the wedge $\frac{E_{t}\left\{\alpha A_{t+1} k_{t+1}^{* \alpha-1}+1-\delta\right\}}{\rho}-1>0$. During the boom, collateral is abundant and unscreened investment is closer to its unconstrained value, i.e. the wedge is smaller, so that the crowding-out effect of screening is less costly.

To conclude, we have shown that, contrary to conventional wisdom, there is no shortage of information in equilibrium. Although this result may appear surprising to most readers, it is quite natural given that entrepreneurs fully appropriate the benefits of screened investment. Clearly, things would change in the presence of distortions that prevented such appropriation. We briefly explore two sources of such distortions in the next section. 


\subsection{Frictional markets and learning-by-doing}

A first set of distortions are those that directly affect the market for screened capital. In particular, assume that - instead of being perfectly competitive - trading in this market is attained by matching: every time an old entrepreneur goes to the market, she is matched with a young entrepreneur and they bargain over the price. The surplus from the transaction is $\frac{\psi\left(s_{t}\right)}{\mu}$, and let us assume that the buyer manages to extract a fraction $\beta$ of this surplus. In this setting, the zero-profit condition for screened investment becomes,

$$
\begin{aligned}
1+\frac{\psi\left(s_{t}\right)}{\mu} & =\frac{E_{t}\left\{\alpha A_{t+1} k_{t+1}^{\alpha-1}+(1-\delta) \cdot\left(1+\frac{\psi\left(s_{t+1}\right)}{\mu}\right)\right\}}{\rho} \\
& -\beta \cdot \frac{1-\delta}{\rho} \cdot \frac{E_{t} \psi\left(s_{t+1}\right)}{\mu},
\end{aligned}
$$

whereas the planner's solution, which depends only on total consumption regardless of its distribution, remains as in the baseline model. Because it prevents entrepreneurs from fully capturing the value of screening upon resale, the matching friction reduces screened investment in the competitive equilibrium. And given that the planner solution is unaffected, it is now possible (if $\beta$ is high enough) for screened investment to be inefficiently low in equilibrium.

A second set of distortions are those that directly affect the technology for screening, such as the presence of dynamic economies of scale. Namely, suppose that $\psi_{t}=\psi\left(s_{t}, k_{t}^{H}\right)$ with $\psi_{1}>0>\psi_{2}$ and $\psi_{1}+\frac{\mu}{\delta} \psi_{2}>0$ : relative to our baseline model, the assumption that $\psi_{2}<0$ can be interpreted as the presence of economy-wide "learning-by-doing," so that the cost of screening falls with the cumulative amount of past screening. In this setting, it is the zeroprofit condition of individual entrepreneurs that remains unchanged, whereas the planner's optimality condition becomes:

$$
\begin{aligned}
1+\frac{\psi\left(s_{t}^{*}, k_{t}^{H *}\right)}{\mu} & =\frac{E_{t}\left\{\alpha A_{t+1} k_{t+1}^{* \alpha-1}+(1-\delta) \cdot\left(1+\frac{\psi\left(s_{t+1}^{*}, k_{t+1}^{H *}\right)}{\mu}\right)\right\}}{\rho} \\
& +\left(\frac{E_{t}\left\{\alpha A_{t+1} k_{t+1}^{* \alpha-1}+1-\delta\right\}}{\rho}-1\right) \cdot \frac{\partial k^{\mu}\left(k_{t+1}^{H *}, q_{t}, A_{t}\right)}{\partial k_{t+1}^{H}} \\
& +\frac{E_{t} \int_{0}^{s_{t+1}^{*}} \psi_{2}\left(x, k_{t+1}^{H *}\right) d x}{\rho} .
\end{aligned}
$$

The atomistic entrepreneurs do not internalize the learning-by-doing externality, but the planner does. As reflected in the last term of Equation (34), the planner understands that, by raising screened investment today, she reduces the expected cost of screening in period $t+1$. 
Once again, it is possible (if the learning-by-doing externality is strong enough) for screened investment to be inefficiently low in equilibrium.

To summarize, even though information depletion amplifies the effects of collateral shocks in the baseline model, there is no shortage of information from a second-best perspective; in fact, information is excessive. This feature of the model is useful, however, because it underscores the precise nature of distortions required for information production to be inefficiently low: namely, those that prevent agents from fully appropriating the benefits of screening.

\section{Testing the mechanism}

We now test the model's predictions 1-3 as outlined in Section 3.3. Doing so is non-trivial for at least two reasons.

First, all three predictions refer to the effect of collateral on the amount and composition of investment. Assessing this in the data requires identifying changes in collateral that are orthogonal to other economic conditions, such as productivity, which may affect investment on their own. The literature has dealt with this problem (i) by identifying exogenous shocks to the value of assets, e.g. real estate, and (ii) by tracing out the effects of these shocks on firm-level outcomes. We will follow the same approach here, although we will complement it with regional-level evidence as well. In particular, we build on Chaney et al. (2012) by extending the period to include the post-2007 housing bust 19 We use their framework to estimate the impact of real estate prices on corporate investment. Specifically, we use local variations in real estate prices as shocks to the collateral value of firms that own real estate to measure the impact of real estate prices on corporate investment.

Second, the main prediction of the model is that an increase in collateral shifts the composition of investment away from screened investment (i.e., with high information content) towards unscreened investment (i.e., with low information content). Assessing this in the data would require a measure of the informational content of investment, which we do not observe. We proceed instead by focusing on firm-level measures of information that are commonly used in the economics and finance literature. Our firm-level results thus correspond to a view of the world in which firms are heterogeneous according to their information: on some firms there is abundant information, and we can think of these as engaging predominantly in screened investment, whereas on others there is little information, and we can think of them as engaging predominantly in unscreened investment.

Our first measure of information is a firm's bid-ask spread on its stock, expressed in percentages. Research has shown that such spreads and other liquidity measures are associated

\footnotetext{
${ }^{19}$ Our sample covers the period 1993-2012, while their sample covers the period 1993-2007.
} 
with information asymmetries in trading activities Amihud and Mendelson, 1986; Huang and Stoll, 1997; Kelly and Ljungqvist, 2012). We therefore interpret a firm's bid-ask spread as an indicator of the lack of public information on the firm by market participants. Concretely, we use the measure of bid-ask spread developed by Corwin and Schultz (2012), which is constructed from daily high and low stock prices by computing high-low ratios over 1-day and 2-day intervals ${ }^{20}$ They show that this measure of bid-ask spreads dominates other commonly used measures, including the Roll (1984) covariance spread estimator, both in capturing the cross-section of bid-ask spreads and month-to-month changes in spreads. In what follows we refer to the bid-ask spread of firm $i$ during year $t$ as Spread $_{i t}$, and assume that it is decreasing in the amount of information on the firm.

As alternative measure of information at the firm level, we use the number of financial analysts that follow a particular firm. Financial analysts produce and disseminate information by aggregating and consolidating it in a way that is more easily digestible for less sophisticated investors (Huang and Stoll (1997)). We follow Chang et al. (2006) and define Analysts $s_{i t}$ as the maximum number of analysts who make annual earnings forecasts for firm $i$ in any month during year $t$, computed using data from the I/B/E/S Historical Summary Files. Contrary to the bid-ask spread, Analysts $s_{i t}$ is increasing in the amount of information on firm $i$.

Finally, as a third measure of information we use the ratio of intangible assets to tangible fixed assets of the sector in which the firm operates. Intangible assets are more difficult to measure than tangible fixed assets (McGrattan and Prescott, 2010; Eisfeldt and Papanikolaou, 2014). This is the main reason intangible investment is largely excluded from the calculation of gross domestic product. As a result, firms operating in sectors that rely more heavily on intangible assets are more difficult to value by investors, i.e., it is relatively difficult to produce

${ }^{20}$ Specifically, the Corwin-Schultz bid-ask spread estimator, $S$, is computed as: $S=\frac{2\left(e^{\alpha}-1\right)}{1+e^{\alpha}}$, where

$$
\begin{array}{r}
\alpha=\frac{\sqrt{2 \beta}-\sqrt{\beta}}{3-2 \sqrt{2}}-\sqrt{\frac{\gamma}{3-2 \sqrt{2}}}, \\
\beta=E\left\{\sum_{j=0}^{1}\left[\ln \left(\frac{H_{t+j}^{o}}{L_{t+j}^{o}}\right)\right]^{2}\right\}, \\
\gamma=\left[\ln \left(\frac{H_{t, t+1}^{o}}{L_{t, t+1}^{o}}\right)\right]^{2},
\end{array}
$$

where $H$ and $L$ denote the observed high and low stock prices, respectively, $\beta$ denotes the square of the log high-low price ratios on 2 consecutive single days, and $\gamma$ denotes the square of the log high-low ratio over a 2-day period. The estimator is based on two assumptions. First, the daily high prices are typically buyer initiated and low prices are seller initiated, and therefore the ratio of high-to-low prices for a day reflects both the fundamental volatility of stock and its bid-ask spread. Second, the volatility component of the high-to-low price ratio increases proportionately with the length of trading interval whereas the component due to bid-ask spreads does not. 
hard information about the investment of firms in these sectors. We follow the approach of Claessens and Laeven (2003) and use the ratio of intangible assets to tangible fixed assets at the two-digit SIC sectorial level as proxy for information. This measure, which we denote Intangibility $_{i t}$ and compute at the sectorial level to reduce reverse causality, is decreasing in the amount of information on firm $i$.

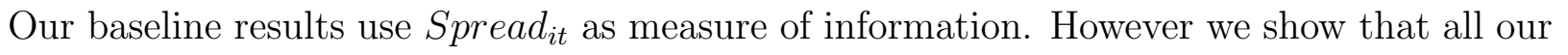
main results are robust to using the two alternative measures of information.

\subsection{Empirical specifications}

Taking the previous points into account, we perform the following empirical exercises. To test for prediction 1 , we estimate - for firm $i$, at date $t$, with headquarters in location $k$ (state or MSA) - the following investment equation,

$$
I_{i t}=\alpha_{i}+\delta_{t}+\beta \cdot R E_{i t}+\gamma \cdot P_{k t}+\text { controls }_{i t}+\varepsilon_{i t}
$$

where $I$ is the ratio of investment (CAPEX) to lagged properties, plant and equipment (PPE), $R E_{i t}$ is the ratio of the market value of real estate assets in year $t$ to lagged PPE, and $P_{k t}$ controls for the level of (residential) real estate prices in location $k$ (at state or MSA level) in year $t$. The inclusion of $P_{k t}$ should allow us to disentangle the collateral effect of a firm's real estate from the general effect of house prices on the local economy, including their effect on banking conditions. Prediction 1 is that $\beta>0$ and significant.

There are two potential sources of endogeneity in the estimation of Equation (35): (i) real estate prices could be correlated with investment opportunities, and; (ii) the firm's decision to own real estate could be correlated with its investment opportunities. To address the first, we run as a first stage - for MSA $k$, at date $t$ - the following equation predicting real estate prices $P_{k t}$,

$$
P_{k t}=\alpha_{k}+\delta_{t}+\gamma \cdot \text { Elasticity }{ }_{k} \times R_{t}+v_{k t}
$$

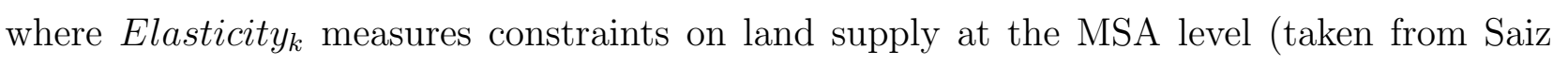
(2010) $), R_{t}$ is the nationwide real interest rate at which banks refinance their home loans, $\alpha_{k}$ is an MSA fixed effect, and $\delta_{t}$ captures macroeconomic fluctuations in real estate prices. Low values of local housing supply elasticity correspond to MSAs with relatively constrained land supply. We expect the coefficient $\gamma$ to be positive, indicating that the positive effect of declining interest rates on prices is stronger in MSAs with less elastic supply. To address the second source of endogeneity we follow Chaney et al. (2012) and control for initial characteristics of firm $i$, denoted by $X_{i}$, interacted with real estate prices $P_{k t}$. Vector $X_{i}$ includes controls that are likely to influence the ownership decision: in particular, it includes five quintiles of age, 
assets, and return on assets, two-digit industry dummies, and state dummies.

To test prediction 2, we extend Equation (35) as follows,

$$
I_{i t}=\alpha_{i}+\delta_{t}+\beta_{1} \cdot R E_{i t}+\beta_{2} \cdot \operatorname{Spread}_{i t}+\beta_{3} \cdot R E_{i t} \cdot \operatorname{Spread}_{i t}+\gamma \cdot P_{k t}+\text { controls }_{i t}+\varepsilon_{i t},
$$

where Spread $_{i t}$ is the annual average bid-ask spread of the firm and the coefficient of interest is $\beta_{3}$, which we expect to be positive and significant. In other words, increases in the value of collateral increase investment, but especially for those firms on which available information as captured by a high value of Spread $_{i t}$ - is lowest.

Being estimated at the firm level, one may wonder whether the firm-level effects that we find in specification (37) carry over to the aggregate level. To address this, we run the following regression at the state level,

$$
\left(\frac{I_{H S}}{I}\right)_{k t}=\alpha_{k}+\delta_{t}+\beta \cdot R E_{k t}+\gamma \cdot P_{k t}+v_{k t}
$$

where $\left(\frac{I_{H S}}{I}\right)_{k t}$ is the investment rate of high spread firms relative to the investment rate of all firms in state $k$ in year $t$, computed by aggregating investment and lagged PPE at the state level separately for high- and low-spread firms, and $R E_{k t}$ is the ratio of the market value of real estate assets normalized by lagged PPE, aggregated at the state level. High-spread firms are defined as firms with spreads above the median. This regression is run at the state and not at the MSA level so that we can cover all firms that are active in the state, and not just the subset of those located in an MSA. Moreover, we run it both for the full sample period and for the boom period between 2001 and 2006, which witnessed the largest increase in house prices, thereby making it more likely that increases in collateral are driven by the housing boom as opposed to other factors. The regression includes year- and state-level fixed effects. The coefficient of interest is $\beta$, which we expect to be positive and significant: an increase in the value of real estate assets implies that a larger proportion of investment goes to high-spread firms.

Finally, to test prediction 3, we would like to show that a prolonged period of unscreened investment makes the ensuing downturn more severe. To test this, we run the following specification,

$$
I_{k t}=\alpha_{k}+\delta_{t}+\beta_{1} \cdot R E_{k t}+\beta_{2} \cdot R E_{k t} \cdot\left(\Delta \frac{I_{H S}}{I}\right)_{k}^{\text {boom }}+\gamma \cdot P_{k t}+v_{k t} .
$$

The dependent variable is the aggregate investment rate at the state level, $R E_{k t}$ is the ratio of the market value of real estate assets normalized by lagged PPE, aggregated at the state 
level, and $\left(\Delta \frac{I_{H S}}{I}\right)_{k}^{b o o m}$ is the change in the share of state-level investment undertaken by highspread firms during the boom years between 2001 and 2006. The underlying idea is that this share captures the increase of uninformed investment at the state level. We estimate this regression during the bust period between 2007 and 2012, when national housing prices collapsed. The regression includes state- and year-fixed effects. ${ }^{21}$ The coefficient of interest is $\beta_{2}$, which we expect to be positive and significant: the larger is the proportion of investment that is undertaken by high-spread firms during the boom, the larger is the drop in investment that is associated to the fall in collateral values during the bust.

\subsection{Data}

Our analysis uses accounting data from COMPUSTAT on US listed firms, merged with real estate prices at the state and Metropolitan Statistical Area (MSA) level, daily stock return and high-low price data from CRSP, and analyst coverage data from the I/B/E/S Historical Summary Files. The construction of the dataset mimics that of Chaney et al. (2012) to which we add measures of information and we also expand the sample to 2012 in order to cover the post-2007 housing bust. Because the accumulated depreciation on buildings is not available in COMPUSTAT after 1993, our sample is restricted to firms active in 1993 with non-missing total assets (COMPUSTAT item No. 6). We keep firms whose headquarters are located in the United States and exclude from the sample firms operating in the construction, finance, insurance, real estate, and mining industries. We require firms to have available data every consecutive year they appear in the sample, and keep only firms that appear at least three consecutive years in the sample. This leaves a sample of 2,855 firms and 35,430 firm-year observations for the period 1993 to 2012.

Market value of real estate assets. Real estate assets include buildings, land and improvement, and construction in progress. These assets are not marked-to-market but valued at historical cost. To recover their market value, we follow the procedure in Chaney et al. (2012), which calculates the average age of those assets and uses historical prices to compute their current market value. The ratio of the accumulated depreciation of buildings (COMPUSTAT item No. 253) to the historic cost of buildings (COMPUSTAT item No. 263) measures the proportion of the original value of a building that has been depreciated. Based on a depreciable life of 40 years, we compute the average age of buildings for each firm. We infer the market value of a firm's real estate assets for each year in the sample period (1993-2012) by inflating their historical cost with state-level residential real estate inflation after 1975, and CPI inflation before 1975. We use the headquarter location (COMPUSTAT variables STATE

\footnotetext{
${ }^{21}$ Equation $(39)$ does not separately include $\left(\Delta \frac{I_{H S}}{I}\right)_{k}^{b o o m}$ because it is absorbed by state fixed effects.
} 
and COUNTY) as a proxy for the location of real estate.

Investment. We compute investment rate as the ratio of capital expenditures (COMPUSTAT item No. 128) to the lagged value of Property Plant and Equipment (COMPUSTAT item No. 8).

Control variables. We compute the Market-to-Book ratio as the total market value of equity divided by the book value of assets (COMPUSTAT item No. 6), and we use the one year lagged value of this ratio in the investment regression. We compute the market value of equity as the number of common stocks (COMPUSTAT item No. 25) times end-of-year close price of common shares (COMPUSTAT item No. 24) plus the book value of debt and quasi equity, computed as book value of assets (COMPUSTAT item No. 6) minus common equity (item No. 60) minus deferred taxes (COMPUSTAT item No. 74). The cash ratio is the ratio of cash flows (COMPUSTAT item No. 18 plus item No. 14) to the lagged value of PPE (COMPUSTAT item No. 8). In most of the regression analysis, we use initial characteristics of firms to control for the potential firm heterogeneity. These controls, measured in 1993, are Return on Assets (operating income before depreciation (COMPUSTAT item No. 13) minus depreciation (COMPUSTAT item No. 14) divided by Assets (COMPUSTAT item No. 6)), Size measured as the natural logarithm of Assets, Age measured as number of years since IPO, two-digit SIC codes and state of headquarters' location. All variables defined as ratios are winsorized using as thresholds the median plus/minus five times the interquartile range.

Real estate price data. We use data on residential real estate prices, both at the state and at the MSA level. Residential real estate prices come from the Office of Federal Housing Enterprise Oversight (OFHEO). The OFHEO Home Price Index (HPI) is a broad measure of single-family home prices in the United States. We match the state level HPI with our accounting data using the state identifier from COMPUSTAT. To match the MSA level HPI, we aggregate Federal Information Processing Standards codes from COMPUSTAT into MSA identifiers using a correspondence table available from the OFHEO website.

Land supply. Controlling for the potential endogeneity of local real estate prices in an investment regression is an important step in our analysis. Following Chaney et al. (2012), we instrument local real estate prices using the interaction of long-term interest rates and local housing supply elasticity. Local housing supply elasticities are provided by Saiz (2010) and are available for 95 MSAs. These elasticities capture the amount of developable land in each metro area and are estimated by processing satellite-generated data on elevation and presence of water bodies. As a measure of long-term interest rates, we use the "contract rate on 30-year, fixed rate conventional home mortgage commitments" from the Federal Reserve's FRED database.

Information. We obtain monthly high-low spread estimates from Corwin and Schultz (2012), 
based on the closed-form solutions for the high-low spread estimator presented in equations (14) and (18) of their paper. Estimates are obtained for all securities available in CRSP and for all months with at least 12 daily observations. These estimates based on CRSP data are then merged to our main dataset of firms included in Compustat using a COMPUSTAT/CRSP concordance table. We use the annual average values for the bid-ask spread, expressed in percentages, of the firm's stock ${ }^{22}$

We construct the analyst coverage variable using data on the number of analysts who make annual earnings forecasts for a firm in a given month using data from the I/B/E/S Historical Summary Files. The intangibility variable is computed as the ratio of intangible assets (item No. 33) to tangible fixed assets (PPE; item No. 8) at the sectorial level for the two-digit SIC code sector in which the firm is operating, constructed annually using data from COMPUSTAT.

Table 1 shows that real estate is a sizable fraction of the tangible assets that corporations hold on their balance sheet. For the median firm in the entire sample, the market value of real estate represents 26 percent of the book value of Property, Plants and Equipment. The information measures indicate that there is much variation in proxies for information across firms in our sample. The median bid-ask spread is $1.36 \%$, with an interquartile range of $1.79 \%$. The median number of analysts covering a firm is 5 with an interquartile range of 9 , and the median ratio of intangible assets is 0.35 with an interquartile range of 0.48 .

\subsection{Empirical Results}

\subsubsection{Firm-level results}

We start our empirical analysis by replicating the results of Chaney et al. (2012) for our extended sample. Table 2 presents the first-stage regression estimates of Equation (36) and Table 3 presents estimates of various specifications of Equation (35). The first-stage regression results confirm the findings of Chaney et al. (2012), even though the impact of local housing supply elasticity on housing prices is somewhat reduced in the extended sample period. As expected, we find that the positive effect of declining interest rates on real estate prices is stronger in MSAs with less elastic supply. Consider the estimates in column 2, for example: they imply that, given a 100-basis-point decline in the interest rate, the increase in real estate prices is 2.3 percentage points higher in cities with high local constraints on land supply (bottom quartile of housing supply elasticity) than in cities with low local constraints (top quartile of housing supply elasticity).

The results in Table 3 broadly confirm those of Chaney et al. (2012). Column 1 shows results

\footnotetext{
${ }^{22}$ We are grateful to Shane Corwin for sharing his data on bid-ask spreads.
} 
for the specification without any additional controls and with real estate prices measured at the state level. The baseline coefficient is 0.062 , implying that each additional $\$ 1$ of real estate collateral increases firm investment by $\$ 0.062$. The effect is economically substantial: it implies that a one-standard deviation increase in real estate collateral raises investment by 24 percent of its standard deviation. Column 2 includes the initial controls interacted with real estate prices to account for observed heterogeneity in decisions to own property, and for its potential impact on the sensitivity of investment to real estate prices. The results are qualitatively unaltered and remain statistically significant at the 1 percent confidence level. Column 3 includes Cash and Market/Book variables. The estimated effect of real estate collateral is somewhat smaller but remains statistically significant at the 1 percent level. Column 4 uses residential prices measured at the MSA level instead of at the state level. The results remain qualitatively similar.

Column 5 shows results of the IV regression in which real estate prices are instrumented using the interaction of interest rates and local housing supply elasticity. More specifically, predicted prices from the estimation of Equation (36) are used as an explanatory variable in Equation (35). We report bootstrapped standard errors, as in Chaney et al. (2012), because these predicted prices are derived from a different sample. The IV estimate of the coefficient on real estate collateral is very close to the OLS estimate and statistically significant at the 1 percent level.

Having confirmed that prediction 1 holds in our sample, we incorporate measures of information to estimate Equation (37). The results are presented in Table 4 . The regressions mimic those in Table 3 with the exception that they include both the one year lagged Spread variable and its interaction with REV alue to capture the differential effect of firm-level information on the effect of real estate collateral on investment. To interpret the regression coefficients, it should be remembered that Spread is decreasing in the degree of firm-level information.

As expected, we find that the positive effect of real estate collateral on investment is more pronounced for firms on which there is less information, as captured through a high bid-ask spread. The estimated effect is economically relevant. Based on the estimates reported in column 1, where we do not include additional controls, a one-standard deviation increase in real estate collateral increases the investment rate of high-spread firms (i.e., Spread at 75th percentile) by 0.8 percentage points more than the investment rate of low-spread firms (i.e., Spread at 25th percentile). This is a sizeable effect compared to the median investment rate of 0.2 . The remaining specifications in Table 4 show that this result is robust to the inclusion of additional initial controls interacted with real estate prices (column 2), the inclusion of Cash and Market/Book variables (column 3), the use of residential prices at the MSA level (column 4), and the instrumenting of real estate prices with local housing supply elasticities 
(column 5).

Table 5 shows that the main results of Table 4 are robust to using alternative measures of information, be it the number of financial analysts who follow a particular firm or the ratio of intangible assets to tangible fixed assets of the sector in which the firm is operating. To interpret the results of Table 5, it is important to remember that Analysts is increasing in information intensity while Intangibility is decreasing in information intensity. Using either measure of information, we find qualitatively similar results for the expected differential impact of information on the effect of real estate collateral on investment. If anything, the estimated effects tend to be larger using these alternative proxies for information. Based on the IV estimates in column 3, for instance, a one-standard deviation increase in real estate collateral increases the investment of firms with low analyst coverage (i.e., 25th percentile of Analysts) by 1.7 percentage points more than the investment of firms with high analyst coverage (i.e., 75th percentile of Analysts).

Taken together, these results suggest that the firm-level evidence from the US is consistent with predictions 1-3 of Section 3.3 .

\subsubsection{State-level results}

We now turn to the state-level results. These are admittedly less tightly identified than our firm-level regressions, and thus more prone to endogeneity concerns. Despite this caveat, they are useful to see verify whether our firm-level results on information, collateral values, and investment carry over to aggregate data.

Table 6 reports estimates of Equation (38), which relates the value of real estate collateral to the share of total investment undertaken by low-information firms at the state level. The estimates in column 1 are based on the full sample while the estimates reported in column 2 are based on the boom period between 2001 and 2006, during which the increase in nationwide house prices - according to the OFHEO real estate price index - exceeded the 75th percentile of such increases. As expected, both specifications point to a positive and significant relationship between increases in the value of firms' real estate collateral and the share of investment undertaken by low-information firms. Moreover, the effect is stronger during boom years, which is when increases in collateral values are more likely to be driven primarily by increases in house prices rather than other factors.

Table 7 reports estimates of Equation (39), which analyzes the relationship between the severity of the fall in investment during downturns and the composition of investment during the boom. In particular, and by focusing on a period of declining collateral values, we test whether the declines in investment during downturns are increasing in the share of investment undertaken by low-information firms during the preceding boom. The sample period 
is restricted to the bust period between 2007 and 2012: during each of these years national house price increases, as measured by the OFHEO real estate price index, was below its 25 th percentile. As in Table 7, the regression is run at the state level. As expected, we find that the drop in investment during the bust period is more pronounced in states that allocated a larger share of investment to low-information firms during the boom.

\section{Conclusions}

This paper has developed a new theory of information production during credit booms. The main insight of the theory is that collateral-driven credit booms are likely to end in deep recessions. The reason is that the abundance of collateral reduces incentives to produce information, which proves costly when collateral values fall. The theory is consistent with existing stylized evidence on the relaxation of lending standards during credit booms, and on the increase and reallocation of investment during real estate booms. We have also shown that the theory's main implications are consistent with firm-level evidence from the US.

Crucially, the theory developed here implies that not all credit booms are alike: in particular, booms that are driven by high collateral values are more likely to end in deep recessions than those driven by productivity. And it suggests that, in order to understand the macroeconomic effects of credit booms, it is crucial to assess their effects on information production. We have taken a first step in this direction by analyzing different proxies for information at the firm

level. But much more remains to be done. Constructing a reliable macroeconomic measure of information production, or - equivalently - of screening intensity, should be instrumental in understanding the nature of different credit booms and their effects. This is a promising and exciting line of research going forward. 


\section{References}

Amihud, Yakov and Haim Mendelson, "Asset pricing and the bid-ask spread," Journal of Financial Economics, 1986, 17 (2), 223-249.

Asea, Patrick K and Brock Blomberg, "Lending cycles," Journal of Econometrics, 1998, $83(1-2), 89-128$.

Bakker, Bas, Giovanni Dell'Ariccia, Luc Laeven, Jérôme Vandenbussche, Deniz Igan, and Hui Tong, "Policies for macrofinancial stability: How to deal with credit booms," Staff Discussion Note No. 12/06, International Monetary Fund 2012.

Becker, Bo, Marieke Bos, and Kasper Roszbach, "Bad times, good credit," Research Paper No. 15-05, Swedish House of Finance 2016.

Caballero, Ricardo and Arvind Krishnamurthy, "Excessive dollar debt: Financial development and underinsurance," Journal of Finance, 2003, 58 (2), 867-893.

Chaney, Thomas, David Sraer, and David Thesmar, "The collateral channel: How real estate shocks affect corporate investment," American Economic Review, 2012, 102 (6), 2381-2409.

Chang, Xin, Sudipto Dasgupta, and Gilles Hilary, "Analyst coverage and financing decisions," The Journal of Finance, 2006, 61 (6), 3009-3048.

Claessens, Stijn and Luc Laeven, "Financial development, property rights, and growth," Journal of Finance, 2003, 58 (6), 2401-2436.

_, Ayhan Kose, and Marco E Terrones, "Financial cycles: what? how? when?," Working Paper No. 11/76, International Monetary Fund 2011.

Corwin, Shane A and Paul Schultz, "A simple way to estimate bid-ask spreads from daily high and low prices," Journal of Finance, 2012, 67 (2), 719-760.

Dávila, Eduardo and Anton Korinek, "Pecuniary externalities in economies with financial frictions," Review of Economic Studies, 2017, 85 (1), 352-395.

Dell'Ariccia, Giovanni and Robert Marquez, "Lending booms and lending standards," Journal of Finance, 2006, 61 (5), 2511-2546.

Diamond, Douglas, Yunzhi Hu, and Raghuram Rajan, "Pledgeability, industry liquidity, and financing cycles," Working Paper No. 23055, National Bureau of Economic Research 2017. 
Doerr, Sebastian, "Collateral, Reallocation, and Aggregate Productivity: Evidence from the US Housing Boom," 2018. Unpublished paper.

Eisfeldt, Andrea and Dimitris Papanikolaou, "The value and ownership of intangible capital," American Economic Review, 2014, 104 (5), 189-94.

Fajgelbaum, Pablo, Edouard Schaal, and Mathieu Taschereau-Dumouchel, "Uncertainty traps," Quarterly Journal of Economics, 2017, 132 (4), 1641-1692.

Favara, Giovanni, "Agency problems and endogenous investment fluctuations," The Review of Financial Studies, 2012, 25 (7), 2301-2342.

Gan, Jie, "The real effects of asset market bubbles: Loan-and firm-level evidence of a lending channel," Review of Financial Studies, 2007, 20 (6), 1941-1973.

García-Santana, Manuel, Enrique Moral-Benito, Josep Pijoan-Mas, and Roberto Ramos, "Growing like Spain: 1995-2007," 2016.

Gopinath, Gita, Şebnem Kalemli-Özcan, Loukas Karabarbounis, and Carolina Villegas-Sanchez, "Capital allocation and productivity in South Europe," Quarterly Journal of Economics, 2017, 132 (4), 1915-1967.

Gorton, Gary and Guillermo Ordoñez, "Collateral crises," American Economic Review, 2014, 104 (2), 343-78.

_ and _ , "Good booms, bad booms," Working Paper 22008, National Bureau of Economic Research 2016.

- and Ping He, "Bank credit cycles," The Review of Economic Studies, 2008, 75 (4), $1181-1214$.

Hsieh, Chang-Tai and Peter J Klenow, "Misallocation and manufacturing TFP in China and India," The Quarterly Journal of Economics, 2009, 124 (4), 1403-1448.

Huang, Roger D and Hans R Stoll, "The components of the bid-ask spread: A general approach," Review of Financial Studies, 1997, 10 (4), 995-1034.

Kelly, Bryan and Alexander Ljungqvist, "Testing asymmetric-information asset pricing models," Review of Financial Studies, 2012, 25 (5), 1366-1413.

Keys, Benjamin J, Tanmoy Mukherjee, Amit Seru, and Vikrant Vig, "Did securitization lead to lax screening? Evidence from subprime loans," The Quarterly journal of economics, 2010, 125 (1), 307-362. 
Krishnamurthy, Arvind and Tyler Muir, "How credit cycles across a financial crisis," Working Paper 23850, National Bureau of Economic Research 2017.

Lisowsky, Petro, Michael Minnis, and Andrew Sutherland, "Economic growth and financial statement verification," Journal of Accounting Research, 2017, 55 (4), 745-794.

Lorenzoni, Guido, "Inefficient credit booms," Review of Economic Studies, 2008, 75 (3), 809-833.

Manove, Michael, A Jorge Padilla, and Marco Pagano, "Collateral versus project screening: A model of lazy banks," Rand Journal of Economics, 2001, pp. 726-744.

Martin, Alberto, "Endogenous credit cycles," 2005.

- and Jaume Ventura, "The macroeconomics of rational bubbles: a user's guide," Annual Review of Economics, 2018, 10, 505-539.

Matsuyama, Kiminori, "Credit traps and credit cycles," American Economic Review, 2007, $97(1), 503-516$.

McGrattan, Ellen R and Edward C Prescott, "Unmeasured investment and the puzzling US boom in the 1990s," American Economic Journal: Macroeconomics, 2010, 2(4), 88-123.

Mendoza, Enrique and Marco Terrones, "An anatomy of credit booms: evidence from macro aggregates and micro data," Working Paper No. 14049, National Bureau of Economic Research 2008.

Nieuwerburgh, Stijn Van and Laura Veldkamp, "Learning asymmetries in real business cycles," Journal of Monetary Economics, 2006, 53 (4), 753-772.

Ordoñez, Guillermo, "The asymmetric effects of financial frictions," Journal of Political Economy, 2013, 121 (5), 844-895.

Peek, Joe and Eric S Rosengren, "Collateral damage: Effects of the Japanese bank crisis on real activity in the United States," American Economic Review, 2000, 90 (1), 30-45.

Petriconi, Silvio, "Bank competition, information choice and inefficient lending booms," 2015. Unpublished paper.

Richter, Björn, Moritz Schularick, and Paul Wachtel, "When to Lean against the Wind," Discussion Paper No. 121882017. 
Roll, Richard, "A simple implicit measure of the effective bid-ask spread in an efficient market," Journal of finance, 1984, 39 (4), 1127-1139.

Ruckes, Martin, "Bank competition and credit standards," Review of Financial Studies, 2004, 17 (4), 1073-1102.

Saiz, Albert, "The geographic determinants of housing supply," Quarterly Journal of Economics, 2010, 125 (3), 1253-1296.

Schularick, Moritz and Alan M Taylor, "Credit booms gone bust: Monetary policy, leverage cycles, and financial crises, 1870-2008," American Economic Review, 2012, 102 (2), 1029-61.

Shleifer, Andrei and Robert Vishny, "Fire sales in finance and macroeconomics," Journal of Economic Perspectives, 2011, 25 (1), 29-48.

Straub, Ludwig and Robert Ulbricht, "Endogenous uncertainty and credit crunches," 2017. 


\section{A Appendix - Tables for Section 6}

Table 1: Summary statistics

\begin{tabular}{|c|c|c|c|c|c|c|}
\hline & Mean & Median & $\mathrm{SD}$ & $\begin{array}{l}25 \text { th } \\
\text { percentile }\end{array}$ & $\begin{array}{l}75 \text { th } \\
\text { percentile }\end{array}$ & Obs. \\
\hline \multicolumn{7}{|l|}{ Firm-level data } \\
\hline Investment & 0.33 & 0.20 & 0.38 & 0.11 & 0.38 & 34986 \\
\hline Cash & 0.04 & 0.26 & 1.78 & -0.09 & 0.63 & 35204 \\
\hline Market / Book & 2.16 & 1.52 & 1.76 & 1.10 & 2.42 & 32512 \\
\hline Spread & 2.26 & 1.36 & 3.07 & 0.77 & 2.56 & 28643 \\
\hline Analysts & 7.93 & 5.00 & 7.46 & 2.00 & 11.00 & 19921 \\
\hline Intangibility & 0.51 & 0.35 & 0.62 & 0.16 & 0.64 & 31167 \\
\hline RE Value (State Prices) & 0.89 & 0.26 & 1.44 & 0.00 & 1.14 & 35430 \\
\hline RE Value (MSA Prices) & 0.88 & 0.26 & 1.42 & 0.00 & 1.13 & 34892 \\
\hline State Prices & 0.29 & 0.24 & 0.12 & 0.20 & 0.33 & 35430 \\
\hline MSA Prices & 0.14 & 0.12 & 0.05 & 0.10 & 0.17 & 34907 \\
\hline Housing Supply Elasticity & 1.17 & 0.90 & 0.67 & 0.65 & 1.42 & 30753 \\
\hline \multicolumn{7}{|l|}{ Initial firm level data (1993) } \\
\hline Age & 8.09 & 8.00 & 4.66 & 3.00 & 13.00 & 2855 \\
\hline ROA & -0.01 & 0.07 & 0.25 & -0.04 & 0.12 & 2844 \\
\hline Log(Asset) & 4.05 & 3.96 & 2.19 & 2.58 & 5.46 & 2852 \\
\hline
\end{tabular}

Notes: Investment is defined as capital expenditure (item No. 128) normalized by the lagged book value of properties, plant and equipment (PPE; item No. 8). Cash is defined as income before extraordinary items + depreciation and amortization (item No. $14+$ item No. 18) normalized by lagged PPE (item No. 8). Market / Book is defined as the market value of assets (item No. 6 + (item No. 60 x item No. 24) - item No. 60 - item No. 74) normalized by their book value (item No. 6). Spread is the annual average bid-ask spread, expressed in percentages, of the firm's stock, from Corwin and Schultz (2011). Analysts is the maximum number of analysts who make annual earnings forecasts in any month over the year, computed following Chang, Dasgupta and Hilary (2006) using data from the I/B/E/S Historical Summary File. Intangibility is the ratio of intangible assets (item No. 33) to tangible fixed assets (PPE; item No. 8) at the sectoral level for the two-digit SIC code sector in which the firm is operating. RE Value is the ratio of the market value of real estate assets normalized by lagged PPE, computed as in Chaney, Sraer and Thesmar (2012). ROA is defined as operating income before depreciation minus depreciation and amortization normalized by total assets ((item No. 13 - item No. 14)/item No. 6). Age is the number of years since IPO. MSA / State Prices is the level of the MSA / State OFHEO real estate price index, normalized to 1 in 2006. Housing Supply Elasticity comes from Saiz (2010). Sample period covers 1993-2012. 
Table 2: First-stage regression: the impact of local housing supply elasticity on housing prices

\begin{tabular}{lll}
\hline VARIABLES & $\begin{array}{l}(1) \\
\text { MSA Prices }\end{array}$ & MSA Prices \\
\hline Housing supply elasticity & $0.00990^{* * *}$ & \\
& $(0.00274)$ & \\
First quartile of elasticity & & $-0.0225^{* * *}$ \\
& & $(0.00682)$ \\
Second quartile of elasticity & & -0.00548 \\
& & $(0.00751)$ \\
Third quartile of elasticity & & 0.00141 \\
& & $(0.00744)$ \\
Year FE & & \\
MSA FE & Yes & Yes \\
Observations & Yes & Yes \\
R-squared & 2232 & 2232 \\
\hline
\end{tabular}

Notes: This table investigates how local housing supply elasticity, as defined by Saiz (2009), affects real estate prices, following Chaney, Sraer and Thesmar (Table 3, 2012). The dependent variable is the residential real estate price index, defined at the MSA level. Column 1 uses the local housing supply elasticity, while column 2 uses quartiles of the elasticity. All regressions control for year as well as MSA fixed effects and cluster observations at the MSA level. T-stats in parentheses. ${ }^{* * *}$ Significant at the 1 percent level. ** Significant at the 5 percent level. * Significant at the 10 percent level. 
Table 3: Investment and collateral

\begin{tabular}{llllll}
\hline & $(1)$ & $(2)$ & $(3)$ & $(4)$ & $(5)$ \\
VARIABLES & OLS & OLS & OLS & OLS & IV \\
& & & & & \\
RE Value (State Prices) & $0.0622^{* * *}$ & $0.0563^{* * *}$ & $0.0478^{* * *}$ & & \\
& $(0.00345)$ & $(0.00361)$ & $(0.00349)$ & & \\
State Prices & $-0.0999^{*}$ & -0.367 & -0.142 & & \\
& $(0.0529)$ & $(0.305)$ & $(0.347)$ & & \\
Cash & & & $0.0253^{* * *}$ & $0.0262^{* * *}$ & $0.0269^{* * *}$ \\
& & & $(0.00241)$ & $(0.00276)$ & $(0.00293)$ \\
Market/Book & & & $0.0577^{* * *}$ & $0.0604^{* * *}$ & $0.0605^{* * *}$ \\
& & & $(0.00282)$ & $(0.00295)$ & $(0.00318)$ \\
RE Value (MSA Prices) & & & & $0.0461^{* * *}$ & $0.0506^{* * *}$ \\
& & & & $(0.00395)$ & $(0.00752)$ \\
MSA Prices & & & & -0.465 & 0.447 \\
& & & & $(1.061)$ & $(0.375)$ \\
Initial Controls x State Prices & No & Yes & Yes & No & No \\
Initial Controls x MSA Prices & No & No & No & Yes & Yes \\
Year FE & Yes & Yes & Yes & Yes & Yes \\
Firm FE & Yes & Yes & Yes & Yes & Yes \\
Observations & 34986 & 34746 & 31351 & 26596 & 22901 \\
Adjusted R-squared & 0.270 & 0.281 & 0.311 & 0.320 & 0.322 \\
\hline
\end{tabular}

Notes: The table reports the empirical link between the value of real estate assets and investment, following Chaney, Sraer and Thesmar (Table 5, 2012). The dependent variable is capital expenditure, normalized by the lagged book value of properties, plant and equipment. Columns 1,2 , and 3 use the state-level residential price index. Columns 4 and 5 use MSA-level residential prices. Except for column 1, all regressions control for firm-level initial characteristics (five quintiles of age, asset, and ROA, as well as two-digit industry and state of location) interactions with Real Estate Prices. All regressions, except columns 1 and 2, control for Cash and previous year Market/Book. Column 5 presents IV estimates where MSA residential prices are instrumented using the interaction of real mortgage rate with the local elasticity of land supply taken from Saiz (2010) (see column 1 in Table 2 for the first-stage regressions). All specifications use year and firm fixed effects and cluster observations at the state-year or MSA-year level. In the IV specification in column 5, standard errors are bootstrapped within MSA-year clusters. T-stats are in parentheses. ${ }^{* * *}$ Significant at the 1 percent level. ${ }^{* *}$ Significant at the 5 percent level. * Significant at the 10 percent level. 
Table 4: Investment, collateral and information

\begin{tabular}{|c|c|c|c|c|c|}
\hline VARIABLES & $\begin{array}{l}\text { (1) } \\
\text { OLS }\end{array}$ & $\begin{array}{l}(2) \\
\text { OLS }\end{array}$ & $\begin{array}{l}3) \\
\text { OLS }\end{array}$ & $\begin{array}{l}(4) \\
\text { OLS }\end{array}$ & $\begin{array}{l}(5) \\
\text { IV }\end{array}$ \\
\hline RE Value (State Prices) & $\begin{array}{l}0.0617^{* * *} \\
(0.00373)\end{array}$ & $\begin{array}{l}0.0474^{* * *} \\
(0.00403)\end{array}$ & $\begin{array}{l}0.0414^{* * *} \\
(0.00405)\end{array}$ & & \\
\hline Spread & $\begin{array}{l}-0.0286^{* * *} \\
(0.00182)\end{array}$ & $\begin{array}{l}-0.0321^{* * *} \\
(0.00183)\end{array}$ & $\begin{array}{l}-0.0209 * * * \\
(0.00173)\end{array}$ & $\begin{array}{l}-0.0214^{* * *} \\
(0.00204)\end{array}$ & $\begin{array}{l}-0.0216^{* * *} \\
(0.00227)\end{array}$ \\
\hline RE Value (State Prices) x Spread & $\begin{array}{l}0.00303^{* * *} \\
(0.000712)\end{array}$ & $\begin{array}{l}0.00438^{* * *} \\
(0.000649)\end{array}$ & $\begin{array}{l}0.00280^{* * *} \\
(0.000708)\end{array}$ & & \\
\hline State Prices & $\begin{array}{l}-0.204^{* * *} \\
(0.0605)\end{array}$ & $\begin{array}{l}-1.052^{* *} \\
(0.452)\end{array}$ & $\begin{array}{l}-0.802^{*} \\
(0.453)\end{array}$ & & \\
\hline Cash & & & $\begin{array}{l}0.0256^{* * *} \\
(0.00282)\end{array}$ & $\begin{array}{l}0.0262^{* * *} \\
(0.00324)\end{array}$ & $\begin{array}{l}0.0268^{* * *} \\
(0.00343)\end{array}$ \\
\hline Market/Book & & & $\begin{array}{l}0.0641^{* * *} \\
(0.00293)\end{array}$ & $\begin{array}{l}0.0645^{* * *} \\
(0.00319)\end{array}$ & $\begin{array}{l}0.0638^{* * *} \\
(0.00346)\end{array}$ \\
\hline RE Value (MSA Prices) & & & & $\begin{array}{l}0.0414^{* * *} \\
(0.00438)\end{array}$ & $\begin{array}{l}0.0462^{* * *} \\
(0.00525)\end{array}$ \\
\hline RE Value (MSA Prices) x Spread & & & & $\begin{array}{l}0.00280^{* * *} \\
(0.000926)\end{array}$ & $\begin{array}{l}0.00280^{* * *} \\
(0.00104)\end{array}$ \\
\hline MSA Prices & & & & $\begin{array}{l}-1.644 \\
(1.066)\end{array}$ & $\begin{array}{l}0.294 \\
(0.351)\end{array}$ \\
\hline Initial Controls x State Prices & No & Yes & Yes & No & No \\
\hline Initial Controls x MSA Prices & No & No & No & Yes & Yes \\
\hline Year FE & Yes & Yes & Yes & Yes & Yes \\
\hline Firm FE & Yes & Yes & Yes & Yes & Yes \\
\hline Observations & 28370 & 28256 & 26535 & 22568 & 19448 \\
\hline Adjusted R-squared & 0.349 & 0.363 & 0.391 & 0.396 & 0.392 \\
\hline
\end{tabular}

Notes: The table reports the empirical link between the value of real estate assets, asymmetric information, and investment. The dependent variable is capital expenditure, normalized by the lagged book value of properties, plant and equipment. Spread is the annual average bid-ask spread, expressed in percentages, of the firm's stock, from Corwin and Schultz (2011). Columns 1, 2, and 3 use the state-level residential price index. Columns 4 and 5 use MSA-level residential prices. Except for column 1, all regressions control for firm-level initial characteristics (five quintiles of age, asset, and ROA, as well as two-digit industry and state of location) interactions with Real Estate Prices. All regressions, except columns 1 and 2, control for Cash and previous year Market/Book. Column 5 presents IV estimates where MSA residential prices are instrumented using the interaction of real mortgage rate with the local elasticity of land supply taken from Saiz (2010) (see column 1 in Table 2 for the first-stage regressions). All specifications use year and firm fixed effects and cluster observations at the state-year or MSA-year level. In the IV specification in column 5, standard errors are bootstrapped within MSA-year clusters. T-stats are in parentheses. *** Significant at the 1 percent level. ${ }^{* *}$ Significant at the 5 percent level. ${ }^{*}$ Significant at the 10 percent level. 
Table 5: Investment, collateral and information: alternative proxies

\begin{tabular}{|c|c|c|c|c|c|c|}
\hline VARIABLES & $\begin{array}{l}\text { (1) } \\
\text { OLS }\end{array}$ & $\begin{array}{l}\text { (2) } \\
\text { OLS }\end{array}$ & $\begin{array}{l}\text { (3) } \\
\text { IV }\end{array}$ & $\begin{array}{l}\text { (4) } \\
\text { OLS }\end{array}$ & $\begin{array}{l}\text { (5) } \\
\text { OLS }\end{array}$ & $\begin{array}{l}\text { (6) } \\
\text { IV }\end{array}$ \\
\hline RE Value (State Prices) & $\begin{array}{l}0.0526^{* * *} \\
(0.00779)\end{array}$ & & & $\begin{array}{l}0.0365^{* * *} \\
(0.00432)\end{array}$ & & \\
\hline RE Value (MSA Prices) & & $\begin{array}{l}0.0510^{* * *} \\
(0.00835)\end{array}$ & $\begin{array}{l}0.0598^{* * *} \\
(0.00982)\end{array}$ & & $\begin{array}{l}0.0346^{* * *} \\
(0.0048)\end{array}$ & $\begin{array}{l}0.0400^{* * *} \\
(0.00569)\end{array}$ \\
\hline Analysts & $\begin{array}{l}0.0238^{* * *} \\
(0.00818)\end{array}$ & $\begin{array}{l}0.0294^{* * *} \\
(0.00846)\end{array}$ & $\begin{array}{l}0.0300^{* * *} \\
(0.00941)\end{array}$ & & & \\
\hline RE Value (State Prices) x Analysts & $\begin{array}{l}-0.00704^{* *} \\
(0.00349)\end{array}$ & & & & & \\
\hline RE Value (MSA Prices) x Analysts & & $\begin{array}{l}-0.00721^{* *} \\
(0.00364)\end{array}$ & $\begin{array}{l}-0.00949^{* *} \\
(0.00396)\end{array}$ & & & \\
\hline Intangibility & & & & $\begin{array}{l}-0.00359 \\
(0.00491)\end{array}$ & $\begin{array}{l}-0.00419 \\
(0.00531)\end{array}$ & $\begin{array}{l}-0.00604 \\
(0.00551)\end{array}$ \\
\hline RE Value (State Prices) x Intangibility & & & & $\begin{array}{l}0.00546^{* *} \\
(0.00249)\end{array}$ & & \\
\hline RE Value (MSA Prices) x Intangibility & & & & & $\begin{array}{l}0.00609 * * \\
(0.00263)\end{array}$ & $\begin{array}{l}0.00673^{* *} \\
(0.0028)\end{array}$ \\
\hline State Prices & $\begin{array}{l}-2.071^{* * *} \\
(0.785)\end{array}$ & & & $\begin{array}{l}-1.075 \\
(0.983)\end{array}$ & & \\
\hline MSA Prices & & $\begin{array}{l}-2.573 \\
(2.359)\end{array}$ & $\begin{array}{l}0.41 \\
(0.532)\end{array}$ & & $\begin{array}{l}-0.648 \\
(2.646)\end{array}$ & $\begin{array}{l}0.854 \\
(0.541)\end{array}$ \\
\hline Cash & $\begin{array}{l}0.0313^{* * *} \\
(0.00442)\end{array}$ & $\begin{array}{l}0.0308^{* * *} \\
(0.00486)\end{array}$ & $\begin{array}{l}0.0303^{* * *} \\
(0.00521)\end{array}$ & $\begin{array}{l}0.0277^{* * *} \\
(0.00304)\end{array}$ & $\begin{array}{l}0.0287^{* * * *} \\
(0.00337)\end{array}$ & $\begin{array}{l}0.0296^{* * *} \\
(0.00355)\end{array}$ \\
\hline Market/Book & $\begin{array}{l}0.0649^{* * *} \\
(0.00388)\end{array}$ & $\begin{array}{l}0.0666^{* * *} \\
(0.00395)\end{array}$ & $\begin{array}{l}0.0665^{* * *} \\
(0.00426)\end{array}$ & $\begin{array}{l}0.0621^{* * *} \\
(0.00311)\end{array}$ & $\begin{array}{l}0.0644^{* * *} \\
(0.00325)\end{array}$ & $\begin{array}{l}0.0644^{* * *} \\
(0.00351)\end{array}$ \\
\hline Initial Controls x State Prices & Yes & No & No & Yes & No & No \\
\hline Initial Controls x MSA Prices & No & Yes & Yes & No & Yes & Yes \\
\hline Year FE & Yes & Yes & Yes & Yes & Yes & Yes \\
\hline Firm FE & Yes & Yes & Yes & Yes & Yes & Yes \\
\hline Observations & 17051 & 14517 & 12432 & 22436 & 19134 & 16510 \\
\hline Adjusted R-squared & 0.452 & 0.469 & 0.471 & 0.371 & 0.379 & 0.380 \\
\hline
\end{tabular}

Notes: The table reports the empirical link between the value of real estate assets, information, and investment. The dependent variable is capital expenditure, normalized by the lagged book value of properties, plant and equipment. Analysts is $\ln (1+\mathrm{A})$, where $\mathrm{A}$ is the maximum number of analysts who make annual earnings forecasts in any month over a 12-month period, computed following Chang, Dasgupta and Hilary (2006) using data from the I/B/E/S Historical Summary File. Intangibility is the ratio of intangible assets to tangible fixed assets at the sectoral level for the two-digit SIC code sector in which the firm is operating. Columns 1 and 4 use state-level residential prices, while Columns 2, 3, 5, and 6 use MSA-level residential prices. All regressions control for firm-level initial characteristics (five quintiles of age, asset, and ROA, as well as two-digit industry and state of location) interactions with Real Estate Prices. All regressions control for Cash and previous year Market/Book. Columns 3 and 6 present IV estimates where MSA residential prices are instrumented using the interaction of real mortgage rate interacted with the local elasticity of land supply taken from Saiz (2010) (see column 1 in Table 2 for the first-stage regressions). All specifications use year and firm fixed effects and cluster observations at the state-year or MSA-year level. In the IV specifications in columns 3 and 6 , standard errors are bootstrapped within MSA-year clusters. T-stats are in parentheses. ${ }^{* * *}$ Significant at the 1 percent level. ${ }^{* *}$ Significant at the 5 percent level. ${ }^{*}$ Significant at the 10 percent level. 
Table 6: Investment, collateral and information: aggregate results

\begin{tabular}{lll}
\hline & $(1)$ & $(2)$ \\
VARIABLES & Aggregate & Boom years (2001-2006) \\
\hline \multirow{2}{*}{ RE Value (State Prices) at State Level } & $0.0308^{* *}$ & $0.0623^{* *}$ \\
& $(0.0134)$ & $(0.0301)$ \\
State Prices & -4.454 & -8.724 \\
& $(2.801)$ & $(5.443)$ \\
& & \\
Year FE & Yes & Yes \\
State FE & Yes & Yes \\
Observations & 900 & 190 \\
R-squared & 0.110 & 0.213 \\
\hline
\end{tabular}

Notes: The table reports the empirical link between the value of real estate assets and the proportion of investment going to low-information firms at the state level. The dependent variable is the investment rate of high spread firms relative to the investment rate of all firms, computed at the state level. Investment rates are computed as capital expenditure, normalized by the lagged book value of properties, plant and equipment. High spread firms are defined as firms with above median levels of spread. Spread is the median value of the annual average bid-ask spread, expressed in percentages, of the firm's stock, from Corwin and Schultz (2011). RE Value (State Prices) at State Level is the ratio of the market value of real estate assets normalized by lagged PPE, computed as in Chaney, Sraer and Thesmar (2012) but aggregated at the state level. State Prices is the level of the state-level OFHEO real estate price index, normalized to 1 in 2006. All specifications include year and state-level fixed effects. The regression in Column 2 limits the sample to the boom period 2001 to 2006, where boom years are defined as years during which national house price growth, according to the OFHEO real estate price index, is above its 75 th percentile. T-stats are in parentheses. *** Significant at the 1 percent level. ${ }^{* *}$ Significant at the 5 percent level. ${ }^{*}$ Significant at the 10 percent level. 
Table 7: Investment, collateral and information: aggregate results during busts

\begin{tabular}{ll}
\hline VARIABLES & $(1)$ \\
\hline$\Delta$ Investment Ratio during Boom at State Level x RE Value (State Prices) at State Level & $0.293^{* * *}$ \\
& $(0.0863)$ \\
RE Value (State Prices) at State Level & $0.0649^{* * *}$ \\
State Prices & $(0.0199)$ \\
& 0.00679 \\
Year FE & $(0.0942)$ \\
State FE & Yes \\
Observations & Yes \\
R-squared & 216 \\
\hline
\end{tabular}

Notes: The table reports the empirical link between the value of real estate assets and investment rates at the state level during bust years, conditional on the proportion of investment going to low-information firms during the boom years. The dependent variable is the aggregate investment rate at the state level during the bust period, with investment rates are computed as capital expenditure, normalized by the lagged book value of properties, plant and equipment. The bust period is 2007 to 2012, where bust years are defined as years during which national house price growth, according to the OFHEO real estate price index, is below its 25 th percentile. $\Delta$ Investment Ratio during Boom at State Level is the increase in the proportion of state-level investment made by high spread firms during the boom period. The boom period is 2001 to 2006 , where boom years are defined as years during which national house price growth, according to the OFHEO real estate price index, is above its 75 th percentile. High spread firms are defined as firms with above median levels of spread. Spread is the median value of the annual average bid-ask spread, expressed in percentages, of the firm's stock, from Corwin and Schultz (2011). RE Value (State Prices) at State Level is the ratio of the market value of real estate assets normalized by lagged PPE, computed as in Chaney, Sraer and Thesmar (2012) but aggregated at the state level. State Prices is the level of the state-level OFHEO real estate price index, normalized to 1 in 2006. All specifications include year and state-level fixed effects. The regression in Column 2 limits the sample to the boom period 2001 to 2006, where boom years are defined as years during which national house price growth, according to the OFHEO real estate price index, is above its 75 th percentile. T-stats are in parentheses. ${ }^{* * *}$ Significant at the 1 percent level. ${ }^{* *}$ Significant at the 5 percent level. * Significant at the 10 percent level. 


\section{B Appendix - Derivations and Extensions (For Online Publication)}

\section{B.1 Screening by competitive intermediaries}

In this section, we microfound the screening technology and the contracts specified in Section

2 as an outcome of an equilibrium in a competitive intermediary sector. For simplicity, we do so for the case in which $\delta=1$, so that there are no purchases of pre-existing units of capital.

Consider that there is a finite number of financial intermediaries or banks, which collect deposits from savers and provide loans and screening services to entrepreneurs. Banks are assumed to be risk neutral and competitive. On the deposit side, they take the gross interest factor on deposits $\rho$ as given. On the loan market, they Nash compete taking the prices as given by designing contracts, which can be of two types: with and without screening services. In what follows, to conserve on notation, we drop the time subscripts from all the variables.

If a contract does not provide screening services, it specifies the investment $I^{\mu}$ that the entrepreneur is required to make, the loan size $L^{\mu}$ that the bank provides to the entrepreneur, and the (possibly state-contingent) repayment $R^{\mu} \cdot L^{\mu}$ that the entrepreneur must make to the bank.

If a contract provides screening services, then the terms of the contract can depend on the type of project/capital being financed, i.e. the investment $I^{\theta}$, loan size $L^{\theta}$ and repayment $R^{\theta} \cdot L^{\theta}$ can all depend on $\theta \in\{L, H\}$. We assume that the screening provided by the banks is verifiable and the result of screening is public information.

We impose the standard assumption that contracts are exclusive, i.e., entrepreneurs can apply to at most the contracts offered by one bank. It is also assumed that each bank gets the same share of total deposits and, if they design the same contract, they get the same share and composition of loan applications.

In order to provide screening services, banks must hire experts. There is a unit mass of such experts, and each expert has the ability to screen at most $n<\infty$ projects (experts could be the savers or a different type of agents, it is inconsequential). We assume that the experts have heterogeneous effort costs $c$ of screening (in terms of consumption goods), which are distributed in the population according to a $\operatorname{cdf} F(c)$ with full support on $[0, \infty)$. The market for experts is competitive, and both experts and banks act as price takers. Given the expert wage $\psi$, banks demand expert services (e.g. how many projects to screen) and experts supply them; the expert market clears when the demand and supply for expert services is equalized.

Let $s$ denote the equilibrium screening services demanded by the banks. Then, for the expert market to clear, the wage $\psi$ must be such that $s=n \cdot F(\psi)$, i.e. the set of experts 
who provide screening services are those with effort cost below $\psi$. This implies an equilibrium screening cost $\psi(s)$ satisfying $\psi(0)=0$ and $\psi^{\prime}(\cdot)>0$, as specified in the text. It is then straightforward to verify that, in equilibrium, the posted contracts that provide screening satisfy:

$$
\begin{aligned}
& L^{L}=I^{L}=R^{L}=0 \\
& L^{H}=I^{H}=\mu \cdot s ; R^{H}=R^{K, H} ; \mu \cdot\left(\frac{E\left\{R^{K, H}\right\}}{\rho}-1\right)=\psi,
\end{aligned}
$$

whereas contracts that do not provide screening satisfy:

$$
I^{\mu}=q+L^{\mu}=\frac{\rho}{\rho-\mu \cdot E\left\{R^{K, \mu}\right\}} \cdot q ; E\left\{R^{\mu}\right\}=\rho
$$

where we assume without loss of generality that entrepreneurs sell their trees and use the proceeds to invest rather than pledging them as collateral. After some relabelling, it is easy to verify that these are the contracts specified in Section 2 .

Even though we solved for the equilibrium under the assumption that $\delta=1$, nothing substantial changes when $\delta<1$. The same equilibrium contracts that are used to finance investment in new units of unscreened capital would also be used to finance the purchase of pre-existing units of unscreened capital. Moreover, there would be a third type of contract offered in equilibrium to fund the purchase of pre-existing units of screened capital, with

$$
L_{b}^{H}=p^{H} \cdot I_{b}^{H} ; R_{b}^{H}=\frac{R^{K, H}}{p^{H}}
$$

where $I_{b}^{H}$ denotes the units of $H$-type capital that the entrepreneur buys, $L_{b}^{H}$ is the loan that the bank extends to the entrepreneur to fund these purchases, and $R_{b}^{H} \cdot L_{b}^{H}$ is the repayment that the entrepreneur must make to the bank.

\section{B.2 Irreversibilities and fire-sales}

Consider an entrepreneur with net worth $q_{t}$ who is borrowing in order to invest in unscreened capital at time $t$. The entrepreneur expects to be able to either liquidate the produced capital for fraction $\chi$ per unit or sell the produced capital at some price $p_{t+1}^{\mu}$.

Let $p_{t}^{\mu}$ denote the price of unscreened capital at time $t$. Given that the cost of producing a unit equals one, if the entrepreneur is credit constrained it must hold that:

$$
\min \left\{p_{t}^{\mu}, 1\right\} \cdot k_{t+1}^{\mu}=q_{t}+f_{t}
$$


whereas, given that old entrepreneurs can liquidate old units and obtain $\chi$,

$$
\mu \cdot E_{t}\left\{r_{t+1}+\max \left\{p_{t+1}^{\mu}, \chi\right\} \cdot(1-\delta)\right\} \cdot k_{t+1}^{\mu}=\rho \cdot f_{t} .
$$

Jointly considered, both expression imply that,

$$
k_{t+1}^{\mu}=\frac{\rho \cdot q_{t}}{\rho \cdot \min \left\{p_{t}^{\mu}, 1\right\}-\mu \cdot E_{t}\left\{r_{t+1}+\max \left\{p_{t+1}^{\mu}, \chi\right\}(1-\delta)\right\}} .
$$

On the other hand, if the entrepreneur is unconstrained, we must have:

$$
\min \left\{p_{t}^{\mu}, 1\right\}=\frac{E_{t}\left\{r_{t+1}+\max \left\{p_{t+1}^{\mu}, \chi\right\} \cdot(1-\delta)\right\}}{\rho} .
$$

Since the cost of production of a unit of unscreened capital is one, market clearing for unscreened capital implies that:

$$
p_{t}^{\mu} \begin{cases}=1 & \text { if } k_{t+1}^{\mu}>(1-\delta) k_{t}^{\mu} \\ \in[\chi, 1] & \text { if } k_{t+1}^{\mu}=(1-\delta) k_{t}^{\mu}, \\ =\chi & \text { if } k_{t+1}^{\mu}<(1-\delta) k_{t}^{\mu}\end{cases}
$$

for all $t$. As for screened investment, we know that entrepreneurs are always unconstrained, so:

$$
p_{t}^{H}=\frac{E_{t}\left\{r_{t+1}+p_{t+1}^{H} \cdot(1-\delta)\right\}}{\rho},
$$

where screening is given by:

$$
s_{t}=\mu^{-1} \cdot \max \left\{0, k_{t+1}^{H}-(1-\delta) k_{t}^{H}\right\} .
$$

The market clearing price of screened capital must therefore be given by:

$$
p_{t}^{H}= \begin{cases}=1+\frac{\psi\left(s_{t}\right)}{\mu} & \text { if } k_{t+1}^{H}>(1-\delta) k_{t}^{H} \\ \in[\chi, 1] & \text { if } k_{t+1}^{H}=(1-\delta) k_{t}^{H} \\ =\chi & \text { if } k_{t+1}^{H}<(1-\delta) k_{t}^{H}\end{cases}
$$

Equations (46)-(51) fully characterize the equilibrium of this economy. 


\section{B.3 Collateral booms and misallocation}

To analyze the impact of booms on misallocation, consider the economy where - for production purposes - each unit of low-quality capital is equivalent to $\lambda<1$ units of high-quality capital. Consider that each unit of capital is operated separately as an independent plant or business unit. Then, to an outside observer, the output produced by an high-quality unit of capital (be it screened or unscreened) will be given by

$$
A \cdot l_{i, t}^{1-\alpha}
$$

and its measured TFP will equal $A$. The output produced by a low-quality unit of capital will instead be given by

$$
A \cdot \lambda^{\alpha} \cdot l_{i, t}^{1-\alpha}
$$

and its measured TFP will equal $A \cdot \lambda^{\alpha}$.

Taking this into account, we can compute the variance of TFP relative to the average:

$$
V A R_{T F P, t}=\frac{k_{t}^{H}+\mu \cdot k_{t}^{\mu}}{k_{t}^{H}+k_{t}^{\mu}} \cdot\left(\frac{A}{\bar{A}_{t}}-1\right)^{2}+\frac{(1-\mu) \cdot k_{t}^{\mu}}{k_{t}^{H}+k_{t}^{\mu}} \cdot\left(\frac{\lambda^{\alpha} \cdot A}{\bar{A}_{t}}-1\right)^{2}
$$

where $(1-\mu) \cdot k_{t}^{\mu}$ denotes the number of low-quality units of capital in this economy and $\bar{A}_{t}$ denotes the average productivity of the economy,

$$
\bar{A}_{t}=\frac{k_{t}^{H}+k_{t}^{\mu} \cdot\left[\mu+(1-\mu) \cdot \lambda^{\alpha}\right]}{k_{t}^{H}+k_{t}^{\mu}} \cdot A \text {. }
$$

Noting that

$$
\frac{A}{\bar{A}_{t}}-1=\frac{(1-\mu) \cdot k_{t}^{\mu}}{k_{t}^{H}+k_{t}^{\mu} \cdot\left[\mu+(1-\mu) \cdot \lambda^{\alpha}\right]} \cdot\left(1-\lambda^{\alpha}\right)
$$

and

$$
\frac{\lambda^{\alpha} \cdot A}{\bar{A}_{t}}-1=\frac{k_{t}^{H}+\mu \cdot k_{t}^{\mu}}{k_{t}^{H}+k_{t}^{\mu} \cdot\left[\mu+(1-\mu) \cdot \lambda^{\alpha}\right]} \cdot\left(\lambda^{\alpha}-1\right)
$$

we can write Equation $(52)$ as,

$$
V A R_{T F P, t}=\frac{\kappa_{t}+\mu}{\left(\kappa_{t}+\mu+(1-\mu) \cdot \lambda^{\alpha}\right)^{2}} \cdot \Lambda
$$

where $\Lambda \equiv(1-\mu) \cdot\left(\lambda^{\alpha}-1\right)^{2}$ is a constant and $\kappa_{t} \equiv \frac{k_{t}^{H}}{k_{t}^{\mu}}$.

The variance of productivity depends only on the ratio of screened to unscreened capital $\kappa$. 
Formally,

$$
\frac{\partial V A R_{T F P, t}}{\partial \kappa_{t}}<0 \Longleftrightarrow \mu+\kappa_{t}>\lambda^{\alpha} \cdot(1-\mu),
$$

which justifies Equation (26). Thus, an increase in $\kappa_{t}$ reduces misallocation if and only if the productivity weighted stock of high-quality capital (i.e., $\mu \cdot k_{t}^{\mu}+k_{t}^{H}$ ) is greater than the productivity weighted stock of low-quality capital (i.e., $\left.\lambda^{\alpha} \cdot(1-\mu) \cdot k_{t}^{\mu}\right)$. In this case, an increase in $k_{t}^{H}$ (or, a reduction in $k_{t}^{\mu}$ ) adds (eliminates) a productivity-weighted unit of capital that is similar to (different from) the average and, in so doing, it reduces dispersion in productivity.

\section{B.4 The planner's problem}

The planner's objective is to maximize the expected present discounted value of aggregate consumption net of screening costs, $E_{0} \sum_{t=0}^{\infty} \rho^{-t} C_{t}$.

Consider the consumption goods available to the planner at time $t$. First, there is total output, given by $A \cdot\left(k_{t}^{H}+k_{t}^{\mu}\right)^{\alpha}$. Second, there is the disinvestment in physical capital $(1-\delta)$. $\left(k_{t}^{H}+k_{t}^{\mu}\right)-k_{t+1}^{H}-k_{t+1}^{\mu}$. Third, the planner must devote $\int_{0}^{s_{t}} \psi(x) d x$ resources for screening if she is to screen $s_{t}$ units of capital, i.e. screening costs of all the experts who have lower screening cost than the marginal expert (see Appendix B.1). Finally, the planner can borrow $f_{t}$ consumption goods from the international market, and she must repay $R_{t} \cdot f_{t-1}$ if she has borrowed $f_{t-1}$ at time $t-1$, which has the property that $E_{t-1} R_{t}=\rho$, i.e. the international financial market breaks even. Therefore, the aggregate consumption at time $t$ is:

$$
C_{t}=A\left(k_{t}^{H}+k_{t}^{\mu}\right)^{\alpha}+(1-\delta)\left(k_{t}^{H}+k_{t}^{\mu}\right)-k_{t+1}^{H}-k_{t+1}^{\mu}-\int_{0}^{s_{t}} \psi(x) d x+f_{t}-R_{t} \cdot f_{t-1}+q_{t} .
$$

We impose the transversality condition, $\lim _{t \rightarrow \infty} \rho^{-t} f_{t-1}=0$, and suppose that $f_{-1}=0$. This immediately implies that:

$$
E_{0} \sum_{t=0}^{\infty} \rho^{-t} C_{t}=E_{0} \sum_{t=0}^{\infty} \rho^{-t} \cdot\left(A_{t} k_{t}^{\alpha}+(1-\delta) k_{t}-k_{t+1}-\int_{0}^{s_{t}} \psi(x) d x+q_{t}\right) .
$$

The recursive formulation in the text is then obtained by simply defining the planner's value at time $t$ to be $V_{t} \equiv E_{t} \sum_{\tau=t}^{\infty} \rho^{-(\tau-t)} \cdot\left(A_{t} k_{t}^{\alpha}+(1-\delta) k_{t}-k_{t+1}-\int_{0}^{s_{\tau}} \psi(x) d x+q_{t}\right)$.

The first-order conditions to the planner's problem of maximizing (59) subject to the constraints (28)-(30) yield:

$$
-\mu \cdot\left(1+\frac{\partial k^{\mu}\left(k_{t+1}^{H}, q_{t}, A_{t}\right)}{\partial k_{t+1}^{H}}\right)-\psi\left(s_{t}\right)+\mu \cdot \frac{E_{t} \frac{d V\left(k_{t+1}^{H}, k_{t+1}^{\mu}, q_{t+1}, A_{t+1}\right)}{d k_{t+1}^{H}}}{\rho}=0,
$$


and

$$
\frac{d V\left(k_{t}^{H}, k_{t}^{\mu}, q_{t}, A_{t}\right)}{d k_{t}^{H}}=\left(\alpha A_{t} k_{t}^{\alpha-1}+1-\delta\right) \cdot\left(1+\frac{\partial k^{\mu}\left(k_{t}^{H}, q_{t-1}, A_{t-1}\right)}{\partial k_{t}^{H}}\right)+(1-\delta) \cdot \mu^{-1} \cdot \psi\left(s_{t}\right) .
$$

Combining these, we get Equation (31) in the main body of the paper, which together with (28)-30 and the transversality condition, $\lim _{t \rightarrow \infty} \rho^{-t} \psi\left(s_{t}\right)=0$, characterizes the solution to the planner's problem.

\section{B.5 Generalized pledgeability}

In this section, we extend our analysis to the more general setting in which the pledgeability of $\theta$-type capital is $\phi_{\theta}$ with $\phi_{H}>\phi_{L}$. The key difference from our baseline setting is that now entrepreneurs will earn profits also from operating $H$-type capital.

\section{The Static Benchmark $(\delta=1)$}

We begin with the static benchmark, that is, the economy with $\delta=1$. Let $q^{\mu}$ denote the collateral that entrepreneurs put for unscreened investment. Then in equilibrium, if collateral constraints bind, unscreened investment must be given by:

$$
k^{\mu}=\frac{1}{\rho-\left(\mu \cdot \phi_{H}+(1-\mu) \cdot \phi_{L}\right) \cdot r} \cdot \rho \cdot q^{\mu},
$$

whereas screened investment is given by:

$$
k^{H}=\frac{1}{\rho+\rho \cdot \frac{\psi}{\mu}-\phi_{H} \cdot r} \cdot \rho \cdot\left(q-q^{\mu}\right),
$$

where $q-q^{\mu}$ is the collateral put up for screened investment.

The entrepreneurs' profits associated with each type of investment are:

$$
\begin{aligned}
\Pi^{\mu} & =\left(1-\mu \cdot \phi_{H}-(1-\mu) \cdot \phi_{L}\right) \cdot r \cdot k^{\mu} \\
\Pi^{H} & =\left(1-\phi_{H}\right) \cdot r \cdot k^{H} .
\end{aligned}
$$

In equilibrium, it must be that the entrepreneur is indifferent whether to allocate an additional unit of collateral to unscreened investment:

$$
\frac{\partial \Pi^{\mu}}{\partial q^{\mu}}+\frac{\partial \Pi^{H}}{\partial q^{\mu}}=0
$$


Using the equations $62-(65)$, we have:

$$
1+\frac{\psi}{\mu}=\frac{1-\phi_{H}}{1-\mu \cdot \phi_{H}-(1-\mu) \cdot \phi_{L}}+\frac{(1-\mu) \cdot\left(\phi_{H}-\phi_{L}\right)}{1-\mu \cdot \phi_{H}-(1-\mu) \cdot \phi_{L}} \cdot \frac{r}{\rho} .
$$

Therefore, as in our benchmark economy, an increase in $q$ leads to an increase in $k^{\mu}$, a decrease in $r$, and thus a decrease in screening. Intuitively, in equilibrium the $H$-type projects yield the same return as $L$-type projects but are more levered because they are more pledgeable. Hence, their profits (per unit of collateral) are more sensitive to changes in $r$, i.e. decrease by more when $r$ increases. Thus, in equilibrium, the cost of screening must decline to keep entrepreneurs indifferent between screened and unscreened projects.

The agents in our economy resort to screening because collateral is scarce ( $q$ is small) and screening allows them to identify projects that can be funded with less of it. Therefore, it should not be surprising that the equilibrium of an economy with scarce collateral exhibits more screening than that of an economy with abundant collateral. What is rather specific to the static benchmark is that this effect is monotonic. As we show next, in the dynamic economy, the effect of collateral on screening can be non-monotonic.

\section{The Dynamic Economy $(\delta<1)$}

We now set $\delta<1$ and extend the analysis to the dynamic economy. By the same reasoning as before, the stock of unscreened capital is given by:

$$
k_{t+1}^{\mu}=\frac{\rho}{\rho-\left(\mu \cdot \phi_{H}+(1-\mu) \cdot \phi_{L}\right) \cdot\left(E_{t} r_{t+1}+1-\delta\right)} \cdot q_{t}^{\mu},
$$

whereas the screened capital is given by:

$$
k_{t+1}^{H}=\frac{\rho}{\rho+\rho \cdot \frac{\psi_{t}}{\mu}-\phi_{H} \cdot E_{t}\left\{r_{t+1}+\left(1+\frac{\psi_{t+1}}{\mu}\right) \cdot(1-\delta)\right\}} \cdot\left(q-q^{\mu}\right)
$$

The entrepreneurs' expected profits are now given by:

$$
\Pi_{t}^{\mu}=\left(1-\mu \cdot \phi_{H}-(1-\mu) \cdot \phi_{L}\right) \cdot E_{t}\left\{r_{t+1}+1-\delta\right\} \cdot k_{t+1}^{\mu}
$$

and

$$
\Pi_{t}^{H}=\left(1-\phi_{H}\right) \cdot E_{t}\left\{r_{t+1}+\left(1+\frac{\psi_{t+1}}{\mu}\right) \cdot(1-\delta)\right\} \cdot k_{t+1}^{H} .
$$

Note that, in contrast to the static benchmark, the high resale price of screened capital implies that its return is higher than that of unscreened capital. 
As before, it must hold in equilibrium that the entrepreneur is allocating collateral optimally between screened and unscreened investment:

$$
\frac{\partial \Pi_{t}^{\mu}}{\partial q_{t}^{\mu}}+\frac{\partial \Pi_{t}^{H}}{\partial q_{t}^{\mu}}=0
$$

Using the equations 67 - 670 , we have that:

$$
1+\frac{\psi_{t}}{\mu}=\frac{1-\phi_{H}+(1-\mu) \cdot\left(\phi_{H}-\phi_{L}\right) \cdot \frac{E_{t}\left\{r_{t+1}+1-\delta\right\}}{\rho}}{\left(1-\mu \cdot \phi_{H}-(1-\mu) \cdot \phi_{L}\right) \cdot \frac{E_{t}\left\{r_{t+1}+1-\delta\right\}}{\rho}} \cdot \frac{E_{t}\left\{r_{t+1}+\left(1+\frac{\psi_{t+1}}{\mu}\right) \cdot(1-\delta)\right\}}{\rho} .
$$

Thus, for a given expected screening cost $E_{t} \psi_{t+1}$, there are now conflicting effects of an increase in the value of collateral $q_{t}$. Any such increase reduces $E_{t} r_{t+1}$ : but while this raises the first term on the right-hand-side of the expression, it reduces the second term.

Since the screening cost in the future is also endogenous to collateral values, in order to determine when each force dominates, it is useful to consider the steady state to which the economy converges if $q_{t}=q$ for sufficiently long. In this case, the steady state cost of screening is given by:

$$
1+\frac{\psi}{\mu}=\frac{\Phi(r)}{1-\Phi(r) \cdot \frac{1-\delta}{\rho}} \cdot \frac{r}{\rho}
$$

where

$$
\Phi(r)=\frac{1-\phi_{H}}{\left(1-\mu \cdot \phi_{H}-(1-\mu) \cdot \phi_{L}\right) \cdot \frac{r+1-\delta}{\rho}}+\frac{(1-\mu) \cdot\left(\phi_{H}-\phi_{L}\right)}{1-\mu \cdot \phi_{H}-(1-\mu) \cdot \phi_{L}},
$$

and where $r$ is the steady state marginal product of capital (which is decreasing in $q$ ). We now show that $\psi$ is monotonically increasing in $r$ provided collateral constraints are not too tight.

Differentiating $\psi$ in Equation 72 w.r.t. $r$, we have:

$$
\frac{\partial\left(1+\frac{\psi}{\mu}\right)}{\partial r}=\left(1+\frac{\psi}{\mu}\right) \cdot\left(\frac{1}{r}+\frac{\Phi^{\prime}(r)}{\Phi(r) \cdot\left(1-\Phi(r) \cdot \frac{1-\delta}{\rho}\right)}\right)
$$

which is positive if and only if:

$$
\frac{(1-\mu) \cdot\left(\phi_{H}-\phi_{L}\right)}{1-\mu \cdot \phi_{H}-(1-\mu) \cdot \phi_{L}}>\left(1-\phi_{H}\right) \cdot \frac{\left(\frac{r+1-\delta}{\rho}-1\right) \cdot(1-\mu) \cdot\left(\phi_{H}-\phi_{L}\right) \cdot \frac{1-\delta}{\rho}}{\left(1-\phi_{H}\right) \cdot \frac{r}{\rho}+(1-\mu) \cdot\left(\phi_{H}-\phi_{L}\right) \cdot \frac{r+1-\delta}{\rho} \cdot\left(1-\frac{1-\delta}{\rho}\right)} .
$$

Note that this inequality is satisfied when $\frac{r+1-\delta}{\rho} \approx 1$. Furthermore, because the RHS is increasing in $r$, there is an upper bound $\bar{r}$ such that the inequality (73) is satisfied for $r<\bar{r}$. 
Furthermore, the upper bound $\bar{r}$ increases to $\infty$ as $\phi_{H}$ goes to 1 . This puts a lower bound on the steady state capital stock that is consistent with inequality (73). Since the lowest capital stock is attained when $q_{t}=\underline{q}$, a sufficient condition for screening to be declining in collateral values (in steady state) is that $\underline{q}$ not be too low.

Thus, all the main results of the paper extend to this more general case as long as collateral is not too low. When (73) is not satisfied for some values of $q$, then screening can be nonmonotonic in collateral values. Even in this case, however, screening unambiguously decreases with collateral values if the increase in collateral takes entrepreneurs from being constrained to being sufficiently closed to unconstrained: this is because, at that point, collateral is abundant and the benefits of screening are low.

\section{B.6 Screening pre-existing projects}

In our main analysis, we had assumed that only new projects (or units of capital) can be screened. But note that if an entrepreneur undertakes unscreened investment, then when old she will know its type, depending on whether she is able to abscond with the resources of the project or not. It would then be profitable for her to screen $H$-type units of capital, which would be certain to produce a positive signal and thus command a higher price in the market. We now allow for this possibility.

Because the equilibrium price of $L$-type capital will still be weakly below that of unscreened, entrepreneurs will never pay to screen a project that they know is an $L$-type. Therefore, we only need to consider whether it is worthwhile for an old entrepreneur to screen a project once she finds out that it is $H$-type. If only new projects were screened in equilibrium, then the price of a unit of $H$-type capital would equal $1+\frac{\psi_{t}}{\mu}$ as before. But then an old entrepreneur who has an $H$-type project can deviate and screen it at cost $\psi_{t}$ (by paying out of pocket) and

sell it in the market for a net profit of $\left(\frac{1}{\mu}-1\right) \cdot \psi_{t}>0$. Hence, it must be that at least some pre-existing projects are screened as well.

Thus, it follows that any equilibrium in which new projects are screened also entails screening of pre-existing $H$-type units of capital. This implies that at any time $t$, the equilibrium may feature one of the following three possibilities. First, all pre-existing $H$-type projects are screened, and new projects are screened until the profits from doing so are driven to zero. Second, pre-existing $H$-type projects are only partially screeened, until all profits from screening are exhausted, and no new projects are screened. Finally, the equilibrium may feature screening of all pre-existing $H$-type projects but no screening of new projects because expected profits from such screening are negative.

In the first case, the equilibrium is as before described by equations (10)-12, together with 
the equilibrium screening that is now given by:

$$
s_{t}=\max \left\{0, \frac{k_{t+1}^{H}-(1-\delta) \cdot k_{t}^{H}}{\mu}+\mu \cdot(1-\delta) \cdot k_{t}^{\mu}\right\} .
$$

A sufficient condition for this to be an equilibrium is that $k_{t+1}^{H} \geq(1-\delta) \cdot k_{t}^{H}$. Note that, since $k_{t}^{\mu}$ is increasing in collateral $q_{t}$, the economy will be in this region whenever collateral is scarce enough. Importantly, the qualitative behavior of an economy that is always in this region would be the same as that of our baseline economy, with the exception that the screening of some new projects would be replaced by the screening of pre-existing projects.

In the second case, only a fraction $\sigma_{t} \in(0,1)$ of pre-existing $H$-type projects are screened and new projects are not. The equilibrium dynamics are given by $(10)$, together with

$$
s_{t}=\sigma_{t} \cdot \mu \cdot k_{t}^{\mu}
$$

and where:

$$
k_{t+1}^{H}=s_{t}+(1-\delta) \cdot k_{t}^{H} .
$$

A sufficient condition for this to be an equilibrium is that:

$$
1+\psi\left(s_{t}\right)=p_{t}^{H}=\frac{E_{t}\left\{r_{t+1}+(1-\delta) \cdot p_{t+1}^{H}\right\}}{\rho}<1+\frac{\psi\left(s_{t}\right)}{\mu}
$$

i.e. old entrepreneurs are indifferent to whether to screen pre-existing projects or not. Again, in this region, the qualitative behavior of the economy would be the same as that of our baseline economy, with the exception that now the marginal screened projects are the preexisting ones. Thus, when collateral values increase, it is the screening of these projects that is crowded out.

Finally, in the third case, the equilibrium dynamics are given by Equation (10), together with the equilibrium screening that is now given by:

$$
s_{t}=\mu \cdot(1-\delta) \cdot k_{t}^{\mu},
$$

and where:

$$
k_{t+1}^{H}=s_{t}+(1-\delta) \cdot k_{t}^{H} .
$$

A sufficient condition for this to be an equilibrium is that:

$$
1+\psi\left(s_{t}\right) \leq p_{t}^{H}=\frac{E_{t}\left\{r_{t+1}+(1-\delta) \cdot p_{t+1}^{H}\right\}}{\rho}<1+\frac{\psi\left(s_{t}\right)}{\mu} .
$$


i.e. it is worthwhile to screen all pre-existing unscreened projects but not any new ones. In this region, screening at time $t$ does not respond to changes in collateral values, but an increase in collateral values will increase the stock of unscreened projects and, thus, mechanically equilibrium screening in the next period. Thus, in this region, collateral values and screening dynamically become complements.

\section{B.7 Parameter values for Figures 1 to 9}

In Table 8, we report the parameter values used to produce all the figures. The functional form for the cost of screening is as follows: $\psi\left(s_{t}\right)=a \cdot s_{t}^{b}$. The parameter $\lambda$ is only used to produce Figure 7, when we allow for heterogeneous productivities. Figure 8 uses the same parameter values as the other figures, except for $q, \delta$ and $\mu$. These adjustments are ensure that large fire-sales are triggered in the low-collateral state.

Table 8: Parameter values

\begin{tabular}{lll}
\hline \hline Baseline model & & \\
$\alpha$ & 0.2 & Capital share \\
$\delta$ & 0.15 & Depreciation rate \\
$\mu$ & 0.85 & Probability of H-type investment \\
$\rho$ & 1.1 & International interest rate \\
$\lambda$ & 0.95 & Productivity of L-type capital \\
$a$ & 3 & Parameter of the screening cost function \\
$b$ & 2 & Parameter of the screening cost function \\
$\underline{q}$ & 0.049 & Low collateral state \\
$\bar{q}$ & 0.05 & High collateral state \\
$\underline{A}$ & 1 & Low productivity state \\
$\bar{A}$ & 1.0015 & High productivity state \\
$\pi^{s}$ & 0.01 & Probability for a boom to start \\
$\pi^{e}$ & 0.01 & Probability for a boom to end \\
\hline Irreversibilities and fire-sales & & \\
$\chi$ & 0.9 & Conversion factor \\
$\underline{q}$ & 0.035 & Low collateral state \\
$\delta$ & 0.1 & Depreciation rate \\
$\mu$ & 0.75 & Probability of H-type investment \\
\hline \hline
\end{tabular}

